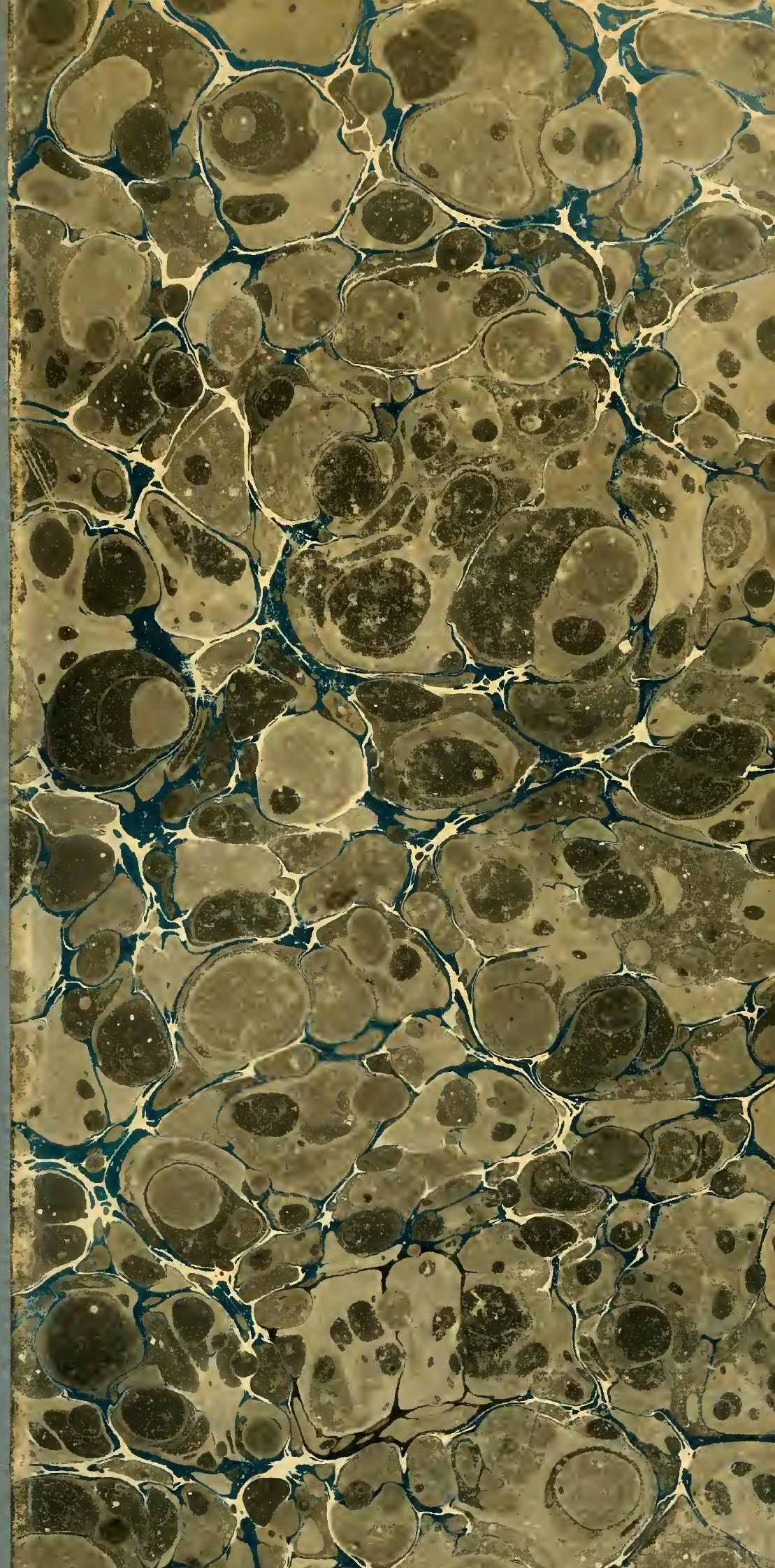







\title{
9
}

\section{ENTOMOGRAPHIAE ROSSICAE}

\author{
A U C T O R E \\ 6. Fiscien de Waldieio。 \\ 121
}

Sapientissimi artis suæ professores sunt, a quilus et propria studia verecunde, et aliena callice estimantur.

Varertus Maximus, Vili. 19.

Elsi multum abest, quin Entomographia Imperii rossici, species omnes novas hodie detectas contineat, - nam tum temporis, quo fuit incepta, non nisi raræ et incompletæe exstiterunt collectiones,impulsum tamen dedit insignem, nova colligendi, definiendi, describendi. Celeberrimi viri, amore scientix ducti, Adams, Besser, Chaudom, Eversmann, Falderman, Fueischer, Gebler, Hummed, Jaeger, Karelin, Krynichi, Manneruein, Ménétriés, Motschulsкy, Steven, Zubroff, perplurinas detexerunt species insectorum, quæ, ad maximam partem in hoc dia-

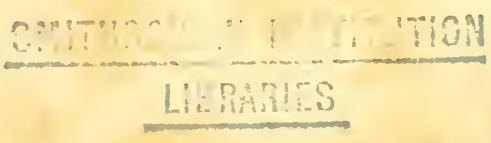


rio descripte exstant. Itinera indefessa a Clar. Adays, Eversuann, Gebler, Jegri, Karemin, Kindermane, Motschulshy, Pander, Steven, Schlienk, 'Tans, Tauscher, Zablotzky instituta, complerunt collectionum divitias, quas itinineratores cum ipsi divulgarunt, tum aliis commiserunt.

orthoptera rossica a me collecta et descripta, in quarto volumine Entomographia rossice mox in lucem eruut prolatura.

neuvropters a Cl. Eversmann solerte fuerunt collecta el partim descripta.

IrxMenopter $A$ intacta restant, sed spero fore ut in Collega nostro Joanne Stepanide BEr editorem diligentem et adcuratum iuveniant.

IEPIDOPTERA, Entomologis nostris distinctissimis, EversMann, Ménétrués, Sodofsky, Gimmertula observata debent egregia eaque nova.

diptera non neglexerunt, Eversmane, Gimmertinal, Fiscuer.

IrEmiptera sola hucusque examinatorem desilerant. Sol ot ordo insectorum hic in colligendis hisce insectis $\mathrm{Si}$ birixe orienfalis a Sodali nostro Sedakoff non neglectus fuit, ita ut lixc collectio rite definila, conspectum lujus ordinis hueusque neglecti, nisi completum, sufficientem tamen offerre poterit.

Mihi proposucram hoc in spicilegio sola insecta Imperii rossici collectionis mea indicare, quae post editionem Entomographix rossica acquisivi et qua mihi nova adparuerunt. - Dein consultius et utilius putavi exponere, nominatim certe, sed syste- 
malice et critice, ommes insectormm rossicorum species, qua et ab aliis fuermu indicatas ec descripter. Mox vero tanti laboris mole obstupui,denique ad prinum propositum me revocavi.

Collectio insectornm Steveniana et Escholtziana, nune Universitalis, complementum Faunc insectorum rossica continent egregium et ditissimum. Varia species prioris $\left(^{*}\right)$ brevi phrasi indicata, hic non repetenda mili visa sunt. Lt taceam de mutatione nominum multarum specierum novarum collectionis mee, qua necessaria silentio pratereunda, ne synonymia perperam angeatur.

(") Muscum historia naluralis Universilatis Casalec mosquensis. P. II. Insecta. Mosqux. 1829. 8. 


\title{
COE
}

\section{PENTAMERA.}

\section{* CICINDELINR.}

\author{
GICINDELA $L$.
}

1. Cucindela Burmeisteri.

Tab. 1. f. 1.

C. fusco-corulca, fere nigrescens; capite thoraceque grisco pilosis; elytris opacis guttulis quatuor flavis.

Long. 8 lin. Lat. 3 lin.

Cicindela Burmeisteri, Fischer Catal. Colcopt. Karel.p. 4. n. 6.

Species insignis quandam offerens similitudinem cum Cicindela aurulenta Buquetii; e Columbia, sed elytris medio dilatatis, forma macularum et imprimis eximia mandibularum longiudine differt.

Caput tenuissine punctatum oculis magnis nigris nitidis. Antennæ allbo-pilosæ, excepto articulo primo longo forti fusco nitido.

Clypeus magnus subcordiformis tlavus. Mandibule basi fusce, apice llavæ. Longitudo apicun mandibularum est ratione latitudinis capitis sub 
oculis ut $2 \%$ ad 2. Palpi fusci splendentes; medii et postici setis longis albis barbati.

Thorax profunde canaliculatus latere raro albopilosus, antice posticeque transversaliter profunde impressus sericeo-nitens.

Elytra medio subdilatata, tenuissime punctata, opaca, fusco-coerulea, vel fere nigra, cum lumine debili coeruleo. Puncta vel macule flave quatuor ita sunt locatæ, ut axillaris paulo major sit vel linearis, secunda et apicalis verum punctum. prosentet, media vero pyriformis adpareat. In Cicindela aurulenta omnia puncta majora sunt excepto axillari, minimo : signum intermedium ad formam fascix transversalis accedit.

Corpus fusco-cyaneum et splendens. Coxæ pedum anteriorum et pedes ipsi ita sunt albo-pilosi, ut color eorum verus vix adpareat; pedes intermedii et postici coerulei, rarius sed longe pilosi. Spinæ dux apicis omnium tibiarum longissimæ et late distantes.

Tarsi pedum anticorum pilis albis densis suffulti, reliquorum graciles elongati, vix pilosi.

Hab. in Songoria rossica. 1). Karelin.

\section{Cicindela Kirilovii.}

Tab. I. f. 3.

C. viridescens, capite thoraceque subaneis; eljetris opacis, punctis axillaribus subdistinctis, fascio mediar et lunula apicali albis. 
Long. 1 lin. Lat, $\$$ lis.

Maximan liabet affinitatem cum C. descendente, (Entom. ross. III. 36 Pl. I. f. 5. Bullet. VIII. p. 160. Pl. VI. f. 1.). sed magnitudine aut potius forma angustiore, colore et delineatione differt. Minor est descendente et angustior. Caput viridi-aneum, levissime punctatum, oculis magnis globosis prominentibus fuscis nilidis. Inter oculos carina albo-notata satis elevata. Clypeus triangularis, basi et apice fuscus, medio flavus. Antennac capite thoraceque longiores, anea.

'Thorax canaliculatus cum impressionibus vulgaribus videtur gracilior et extensior quam in descendente.

Elytra obscure viridi-wenea, fere nigrescentia, rude punctata ; punctis binis axillaribus, descendenti deficientibus, fascia media oblique descendente vix undulata, (sub-simuata in descendente) et lunula apicis albis, quæ hic crassior in C. descendente gracilior adparet.

Corpus infra cyaneum, splendens, pedes graciles nilil observationi offerunt.

IIab. in Songoria rossica. ( $\mathrm{D}^{\text {nus }}$ Karelin).

3. Cicindila lacleola Palias.

C. supra virescens; clytris rarissime granulatis, margine apiceque late intus subundulato sordide albis; abdomine cyaneo. 
Pallas Icon. Tab G. f. 28.

Gehler, Bullet. de Moscou XIV. 1811, p. 57\%. N. 407.

I,ong. 6. lin. Lat. 3. lin.

Ratio partium:

capitis, thoracis, elytrorum.

$\begin{array}{llll}\text { Long. } & 1-2 \% & 1 & 3 \% \\ \text { Lat. } & 1 \% & 2 & 3\end{array}$

Nota. Cum in Cicindelis caput geniculatum sit, mensurx duæ indicandxe sunt, prima longitudo superior, usque ad oculos; secunda facialis s. ab oculis ad apiccm mandibularum.

Caput viridi-æneum nitens, subtilissime punctatum, oculis globosis prominulis, nigris. Clypeus latus flavus. Antenne breves, vix capite thoraceque longiores, articulo primo fortissimo nitenti, reliquis subtilissime griseo-pilosis. Palpi longe albopilosi, ultimo articulo nudo nitido.

Thorax aneus nitens, subtilissime punctatus, profunde canaliculatus. Elytra viridescentia opaca subtilissime granulata, margine late sordide albo, interne vix undulato. Pectus viridi-eneo nitens longe albo-pilosum. Abdomen cyaneum. Pedes ænei nitentes; crura longe albo-pilosa; tarsi postici fitsciculatim alloo-pilosi.

Hab. in Songoria, Karelin; prope Nor-Saisan, Gebler. 
4. Cicindela Schrenkii Gebler.

Tab. I. f. 2.

C. cupro-cenea nitens, eljtris cupreo fuscis subopacis sutura nitente; margine flavo, interne subundulato; abdomine coruleo.

Gebler, Bull. de l'Acad. des Sc. de St. Pétersbourg 1841. Long. 6 lin. Lat. $2 \%$, lin.

Ratio partium :

$\begin{array}{lccc} & \text { capitis } & \text { thoracis elytrorum } \\ \text { Long. } & \%-2 & 1 \% & 4 \\ \text { Lat. } & 1 \% . & 1 \% & 2 \%\end{array}$

Caput æneum nitidum, linea verticis paulo elevata. Oculi fusci, valde prominentes. Palpi fuscoanei, nudi.

'Thorax aneus cum impressionibus vulgaribus. Scutellum abbreviatum, subtriangulare, basi dilatatum.

Elytra angustata a basi ad apicem, obscure anca opaca, sutura ænea nitente, margine late flavo, appice paulo coarctata, intus subundulato. Prosternum cyaneum, nitidum latere dense albo piloso. Abdomen ejusdem coloris et splendens. Pedes omnes viridi-anei, graciles, nitentes, pilis imo setis griseis ubique tectis.

Hab. in Songroria. D. Karelix. 


\section{1}

* C A R A B I C I.

CARABUS. $L$.

* granulati, granulis elcvatis.

5. Carabus Strophium.

C. encus; thorace transwerso, crebre punctulato; elytris obovatis granulatis, granulis clongatis distantibus triplici serie, lineis intermediis subtiliter crenuatis; margine reflexo viridi-eneo.

Long. 9 lin. Lat. $31 / 2$ lin.

PROPORTIO PARTIUM:

$\begin{array}{lccc} & \text { capilis, } & \text { thoracis, } & \text { elytrorum } \\ \text { Long. } & 1 \% & 2 & 6 \\ \text { Lat. } & 1 \% & 2 \% & 3 \%\end{array}$

Carab. Strophium, Fischer, Cat. Col. Karel. p. 4. N. 14. Car. tuberculatus, Ménétriés in literis.

Caput nigrum nitidum punctatum antice utrinque impressum. Antennæ longitudine capitis thoracisque, articulis primis nigris nilidis, reliquis obconicis arcte conjunctis griseo-pilosis. Oculi prominentes globosi fusci.

Thorax rueus nitidus punctatus; late marginatus, canaliculatus; postice impressione lineari transversa. Prosternum in conum longum productum, tenue sulcatum.

Elytra obovata fusco-ænea opaca, marginibus dilatato-reflexis viridi-æneis, granulata, granulis, fuscis elongatis, elevatis, nitidis; lineæ intermedio 
elevatae crenulate s. strophii rosacei ad instar subtiliter grauulatæ.

Corpus infra et pedes nigri picei nitoris.

Hab. in Songoria. D. Karelin.

\section{Carabus microchondrus. $\left(^{*}\right)$}

C. obscure ceneus; thorace transverso marginato punctato; elytris obovatis granulatis, granulis incqualibus, longioribus elongatis cum minoribus oratis alternantibus.

Long. 11 lin. Lat. 5 lin.

Ratio PARTiUm :

$\begin{array}{lccc} & \text { capitis, } & \text { thoracis, } & \text { clytrorum. } \\ \text { Long. } & 2 & 2 \% & 6 \% \\ \text { Lat. } & 1 \% & 3 & 3 \%\end{array}$

Carabus microchondrus, Fiscuer Cat. Col. Karel. p. 5. n. 18.

Caput nigrum nitidum, antice cum impressionibus vulgaribus. Antennx elongatr; capite thoraceque longiores, articulis arcte comnexis.

Thorax transversus punctis scaber, late marginatus, supra canalicalatus, postice cum impressione vulgari. Anguli marginis producti et paulo extrorsum versi. Prosternum latum intumidum, medio impressum, in conum obtusum terminatum.

Elytra obovata opaca granulata, granulis anticis et posticis elongatis, intermediis ovatis mino-

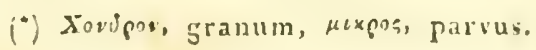


ribus. Margines late reversi seriem punctorum impressorum contiguorum gerentes.

Corpus et pedes nigri nitidi.

Mal. in Songoria. D. Karelix.

\section{Galiabus duarius.}

C. parallelus obscure reneus; thorace transverso subcordato punctato; el tris parallelis punctatim. scabris, granulatis, granulis triplici serie, lineis intcrmediis elevatis utrinque ab alia depressiore concomitatis.

Long. 7 lin. Lat $2 \%$ lin.

Proportio partum:

$\begin{array}{lccc} & \text { capitis, } & \text { thoracis, } & \text { elytrorum. } \\ \text { Long. } & 2 & 2 & 5 \\ \text { Lat. } & 1 \% & 3 & 2 \%\end{array}$

Carabus elongatus, Fiscu. Cat. Col. Karel. p. 4. N. 13.

Propter denominationem nimis relativam nomen mutatum fecit.

Caput productum nigrum nitidum, subtilissime punctulatum, cum impressionibus anticis vulgaribus. Antennæe capite thoraceque multo longiores, articulo primo incrassato, cylindrico admodum longo, tertio aequali.

Thorax ancus transversus, punctatus, canaliculatus, marginatus, marginibus late reflexis et postice productis. Prosternum basi latum, latere pli- 
catum, inter pedes parum angustatum, recta truncatum.

Elytra parallela obscura seriebus tribus granulorum vulgaribus, sed lineæ intermedix elevatæ et incrassate duabus aliis utrinque concomitantur, depressioribus, debilioribus.

Corpus et pedes nigri nitidi.

Hab. in Songoria. D. Karelin.

\section{Carabus gemellus.}

C. thorace subcordiformi marginato subtilissime punctato; elytris granulatis, granulis clevatis irregularibus elongatis hinc illine gemellis, triplici seric.

Long. 10 lin. Lat. 4 lin.

\section{Ratio partium :}

$\begin{array}{lccc} & \text { capitis, } & \text { thoracis, } & \text { elytrorum. } \\ \text { Long. } & 2 \% & 2 & 6 \\ \text { Lal. } & 1 \% & 4 & 4\end{array}$

Magnitudine Car. Kruberi, Bungii, sel elytris parallelis magis elongatis eorumque sculptura nulli accedens.

Caput elongatum tenuissime punctatum, opacum, ante oculos impressionibus profundis. Antennæ nitentes, articulo primo magno conico, secundo el tertio valde abloreviatis.

Thorax transversus subcordatus, marginibus postice valde dilatatis et productis, tenuissime pun- 
ctatus, opacus, medio supra canaliculatus, antice posticeque emarginatus, tenue flavo-ciliatus.

islytra parallela, leviter marginata, punctis clevatis rugosa. 'Triplex scries granulormm elevatorum ita est formata, ut granula quxdam longiora, alia hinc illinc duplicata sint.

Corpus intra nigrum et piceum.

Hab. in Cáucaso.

" punctati, punctis impressis,

\section{Carabus Guerini.}

C. aneus nitidus; thorace cordato viridi aneo; elytris oblongo-oratis punctatis, punctis latis impressis triplici seric; sulcis intermediis tenuissime punctatis.

Long. 11 lin. Lat. G lin.

Proportio partius:

$\begin{array}{lrcc} & \text { capitis, } & \text { thoracis, } & \text { elytrorum } \\ \text { Long. } & 2 \%= & 2 \% & 7 \\ \text { Lat } & 2 & 4 & 5\end{array}$

Carabus Guerini, Fiscuer, Cat. Col. Karel. p. 4. N. 12.

Variat magnitudine. Caput admodum dilatatum, nigrum, nitidum, collo anco, latere irregulariter impressum, medio canaliculatum. Mandibulæ fortissima, supra excavatx. Nentum triplicatum. Antemme fortes subfiliformes, articulis primis quinque nigris nitidis, reliquis coarctatis lanie grisea tectis. 
Thorax cordatus marginatus, viridi-æneus, latere granulatus, medio supra canaliculatus, antice emarginatus flavoque cinctus, postice recta truncatus, marginibus prominentibus reflexis. Prosternum dilatatum, transverse sulcatum.

Elytra oblongo-ovata, cupro-ænea, nitida, punctata, punctis majoribus impressis triplici serie, serie prope suturam paulo minus profunda. Interstitia sulcata sunt et sulci punctulati.

Corpus infra nigrum nitoris picei. Pedes ejusdem coloris, femoribus valde incrassatis, punctis irregularibus impressis.

Nomen illi tributum in honorem Cl. GuerixMeneville, Directoris Societatis Cuvieriani, Entomologiæ aliarumque partium Historiæ naturalis solertissimi promotoris.

Hab. in Songoria. D. Karelin.

\section{Carabus Erichsonii.}

C. thorace viridi-aneo; elytris cupreis longitudinaliter striolatis, punctis impressis triplici serie, media punctis subquadratis adproximatis, externis minus profundis distantibus.

\section{Long. 9 lin. Lat. 3 lin.}

Ratio platiug :

$\begin{array}{lccc} & \text { capitis, } & \text { thoracis, } & \text { elylrorum. } \\ \text { Long. } & 2 & 2 & 5 \\ \text { Liat. } & 1 \%, & 3 \% & 3\end{array}$


Forma et habitus pracedentis. Caput anemm, impressionibus lateralibus profundis. Palpi anteriores longissimi. Antenna basi nigrae splendentes versus apicem obscura, lanugine grisea tecta.

Thorax viridi-ancus marginibus reflexis, antice parum emarginatus, postice recta abscissus, angu-. lis parum prominentibus. Prosterum elevatum, in conum terminatum.

Elytra cuprea subparallela, striolata et punctata, punct is subquadratis impressis triplici seric; series internedia punctis majoribus adproximatis formata, suturalis et marginalis punctis minus profundis et distantibus. Margines punctulati, reflexi, subviolacei.

Corpus infra nigrum, piceum; pedes ejusdem coloris et nitoris.

Hab. in Songoria. D. Karelin.

\section{- 11. Carabus Seclakovii.}

C. obscure ancus, fere fuscus; thorace subquadrato, marginibus reflexis ; elytra obosata, longitudinaliter sulcuta, punctis lutis crebre impressis triplici serie.

Long. 10 lin. Iat. 4 lin.

\section{Prorortio partium:}

\begin{tabular}{|c|c|c|c|}
\hline & calitis, & thoracis, & clytrorum \\
\hline Long. & $23 / 6$ & 2 & 6 \\
\hline Lat. & $g$ & 4 & 4 \\
\hline
\end{tabular}


Caput nigrum nitens, antice longitudinaliter profunde impressum, et latere punctatum, oculis firscis. Mandibule fortes, antice incurvæ supraque profunde impresse. Palpi articulo ultimo valde dilatato. Antennxe articulis crassioribus, primo multo-majori, sequentibus tribus fere aqualibus, nitidis, reliquis obscuris lanie fusca tectis.

Thoras subquadratus latere parum diatatus, margine tenui reflexo, supra punctis irregularibus subrugosus, latere et postice subtiliter punctatus, medio vix canaliculatus s. vestigio canalis, antice posticeque parum emarginatus. Prosternum valde dilatatum, sulco profundo medio.

Elytra obovata fusca opaca, seriebus trinis punctorum latorum aneorum impressorum, inter quas linex tres elevatie læves. Margo reflexus, punctis impressis scaber, cupreus.

Corpus et pedes nigro-picei, cruribus punctatis, tibiis anticis apice incrassatis, oblique truncatis, spinis binis incurvis obtusis.

Hab. in Dauria. D. Sedak of.

\section{Carabue tibialis.}

C. niger, thorace transverso, late marginato; elytris oblongo-ovatis, seriatim punctatis, punctis obscure impressis triplici serie; tibiis anticis subincurvis, apice triangulariter extensis. 
Long. 13 lin. Jat. 3 lin.

\begin{tabular}{|c|c|c|c|}
\hline & capitis, & thoracis, & clytrorum. \\
\hline Long & 3 & 3 & $7 \%$ \\
\hline Lat. & $2 \%$ & $4 \%$ & 5 \\
\hline
\end{tabular}

Carabus tibialis, Fiscuer, Cat. Col. Karel. p. 5.

C. hungaricus, mingens, gastridulus, tibialis primo intuitu tantam habent affinitatem ut difficillime rite distingui posse videantur. Tibialis tibiis anterioribus subincurvis, prostemo profunde impresso, tandem magnitudine cognoscitur.

Caput extensum nigrum nitidum antice latere profunde impressum. Oculi grisei. Antenna nihil notatu dignum offerunt nisi quod primus articulus, totus cylindricus, cum tertio gracili obconico aequalis sit longitudinis.

Thorax transrersus punctis crebris scaber, medio canaliculatus, late marginatus, angulis posticis prominulis, postice submarginatus transversin sulcatus. Prosternum magnum intumidum, conice prolongatum, medio sulco profundo. Scutellum breve subtriangulare, rugosum.

Elytra oblongo-ovata, subopaca, scrialim punctata, punctis obsoletis impressis triplici serie. 'Tertia marginalis rix conspicua. Margo tenuiter reversus, punctis scaber, postice rotundatus.

Corpus infra nigrem nitoris picei.

Nentum globulo nitente ornatum. Prosternum dilatatum, in conum productum, medio fossa pro- 
funda oblonga exseulptum. Pedes postici graciles. antici fortes, coxis magnis semilumaribus, femoribus punctis impressis, tibiis subincurvis, versus apicem triangulariter intumidis, processu obtuso primum articulum tarsorum tegente, spina retrolocata opposita mobili.

Hab. in Sibiria orientali. D. Karelin.

\section{Carabus sploodrinus.}

C. subparallelus niger opacus; thorace quatrato sublyrato; elytris subparallelis postice parum dilatatis, regulariter lineatis, punctis inrequaliter impressis triplici serie: prima suturali $\left(^{*}\right)$ distincta, intermedia obscura, tertia marginali dimidiata.

$$
\text { Long. } 9 \text { lin. Lat. } 3 \% \text {, lir. }
$$

Ratio partium:

$\begin{array}{lccc} & \text { capitis, } & \text { thoracis, } & \text { elytrorum. } \\ \text { Long. } & 2 & 3 & 6 \\ \text { Lat. } & 2 & 3 & 3 \%\end{array}$

Cum. C. Germari forma et habitu comparari potest.

Caput elongatum nigrum opacum antice intu-

$\left({ }^{*}\right)$ Cum series punctorum elytrorum semper ita sint locala ut prima distet a sutura et tertia a margine, spero lore ut termini suturalis et marginalis etiam prope suluram, frope margincm intelligantur. 
midum, latere profunde sulcatum, oculis prominentibus griseis. Antemne articulo primo cylindrico longo nitido, reliquis gracilioriobus obseuris.

'Thorax quadratus, latere antice parum dilatalus, sublyratus, margine parum reflexo, supra canaliculato, punctulato, antice partm emarginatus, postice recta abscissus, ante marginem sulco transverso. Prosternum planum, inter pedes recta truncatum.

Elytra parallela versus apicem parum dilatata, apice subacuminata, supra tenuiter lineata, lineis eleratis, et punetis impressis triplici serie, prima prope suturam regularis et oculis mudis distinguenda, intermedia obscura, tertia s. marginalis incompleta, versus apicem tantum conspicua. Margo leviter rellexus, versus apicem utrinque paulo excisus.

Corpus infra nigrum, nitoris picei; pedes ejusdem coloris et nitoris.

IIab. in Rossia meridionali.

14. Carabus parallelus.

C. parallelus ater nitidus, thorace quadrato marginibus reflexis; elytris clongatis glabris nilidis, apice punctatim scabris, punctis simplicibus impressis triplici serie. 
Long $10 \%$ lin. Lal. 4 lin.

Proportio partium:

$\begin{array}{cccc} & \text { capitis, } & \text { thoracis, } & \text { elytrorum. } \\ \text { Long. } & 3 & 2 & 8 \\ \text { Lat. } & 3 & 2 \%, & 4\end{array}$

Forma et habitu cum C. Neesii Hope convenit, in hoc tamen thorax ad lyriformem accedit.

Caput grlabrum nitidum oculis prominulis griseis. Antennce capite thoraceque multo longriores.

Thorax quadralus convexus glaber nitidus, marginibus reflexis, angulis posticis productis, antice posticeque parum emarginatus. Canalis dorsalis abbreviatus. Scutellum parvum medio sulcatum. Prosternum magnum, conicum, apice subemarginatum.

Elytra thorace vix latiora glabra nitida; submarginata, hinc illinc versus apicem punctura rugulosa. Puncta impressa triplici serie distant imprimis in tertia. Ceterum adhuc quarta series punctorum impressortum minorum et adproximatorum in margine residet.

Corpus et pedes ut in reliquis. Femora anteriora valde intumida, facie interna serie punctorum impressorum.

Hab. in Rossia meridionali.

\section{Caranus Karelini.}

C. niger nitidus; thorace cordato, marginalo, postice alato; elytris orato-subelongatis punctato- 
scabris punctisque impressis obliteratis triplici seric.

Long. $9 \%$ lin. Lat. $3 \%$ lin.

Proportio partiun: (

$$
\text { capitis, thoracis, elytrorum. }
$$

$\begin{array}{llll}\text { Long. } & 2 \% & 2 \% & 7 \\ \text { Lat. } & 2 & 4 \% & 3 \%\end{array}$

Carabus Karelini, Fiscuen Bull. 1830. II. p. 186.

Intermedius inter campestrem et seriatoporum.

Caput latum nigrum splendidum clypeo abbreviato; fronte lineis duabus impressis basi conjunctis, latere impressionibus vulgaribns.

Thorax cordatus punctatus nilidus, marginibus reflexis angustis, postice in alas productis. Canalis dorsalis vestigrium tantum. Margo anticus posticusque recta abscissus. Prosternum latum in conum. terminatum, in fossa profunda mesosterni articulatum.

Elytra elongata subparallela postice rotundata, margine tenui reflexo. Supra punctato-rugosa. Ceterum puncla impressa triplici serie.

Corpus infra nigrum, fere opracum. Pedes anteriores fortissimi; tarsi cleganter a basi ad apicem gradatim dilatatis, unguiculis longis.

Ilab. in Rossia meridionali.

(*) Si mensura partium generalem excedit, cogitandum est, caput plus minusve inclinalum caussam esse. 
16. C.anabus Krjnickii.

C. niger; thorace cordato; elytris oboratis punctato-sulcatis punctisque quadratis impressis triplici serie.

Jong. 13 lin. Lat. 6 lin.

\begin{tabular}{|c|c|c|c|}
\hline & $\begin{array}{l}\text { capitis, } \\
3\end{array}$ & $\begin{array}{c}\text { thoracis, } \\
3 \%\end{array}$ & $\begin{array}{c}\text { elytrorum. } \\
7\end{array}$ \\
\hline Lal. & $3 \%$ & 5 & $5 \%$ \\
\hline
\end{tabular}

Major in hac Caraborum divisione, ceterum punctis quadratis impressis elytrorum, admodum latis facile cognoscendus.

Caput nigrum rugosum. Exceptis impressionibus lateralibus alia media frontis forma V. Antenne, articulo primo longissimo, fortissimo, tertio longiori

'Thorax cordiformis s. transversus marginibus late reflexis angulis posticis valde productis; supra canaliculatus, antice posticeque fere recta abscissus. Scutellum latissimum, totum spatium inter angulos thoracis productos sibi sumens, subtriangulare, postice granulatum. Prosternum magnum convexum, inter pedes utrimque plicatum, apice truncatum.

Elytra obovata elongata opaca, punctis quadralis latis impressis triplici serie. Sulci intermedii, semper terni, crenulati. Margo reflexus seriem contignan punctornm impressorum continet. 
Coppus et pedes nigri parum nitentes.

llab. in Rossia meridionali; Odessee.

Vellem ut denominatio hae lanorem memorim conservet, defuncti professoris Charcoviensis KRYxick de Entomolagria imprimisque de molluscorum studio in Rossia optime meriti.

*.. forcoliti.

17. Carabes ciculricosus.

C. niger, opacus; thorace transserso; elytris foveolatis, foveis crebris continuis subagualibus seriatim positis et granulis eleratis oblongis scriebus binis prope suturam uluimque.

Long. 10 lin. Lat. 4 $1 / 4-5$ lin.

Ratio raRtium:

$\begin{array}{lccc} & \text { capitis, } & \text { thotacis, } & \text { cloterum. } \\ \text { long. } & 3 & 2 \%, & 6 \% \\ \text { Lat. } & 2 \%, 3 \% & 3 \% & 4 \%\end{array}$

Carabus cicalricosus, Fischer Cat. Col. Karcl. p. 5. n. 17.

Species singularis et valke notanda propter foveas elytrorum profunde exsculptas casque quadratas et seriatin contiguas.

Caput magnume productum ruggosum nigrum splendidum, oculis parum prominulis. Palpi fortissimi, ultimo articulo prolongato, apice dilatato. Antenne capite thoraceque vix longiores, primis 
quinque articulis fortibus nigris nitidis, reliquis : subito gracilioribus lanugine fusca tectis.

Thorax transversus rugosus, antice posticeque emarginatus, latere marginibus parum reflexis. Scutellum latum abbreviatum, postice rolundatum granulisque quibusclam elevatis obsitum: Prosternum. latum, fere triangulare, fossa profunda exsculptum.

Elytra thorace vix latiora subparallela, medio parum dilatata, prope suturam utrimque binis serichus granulorum elevatorum tecta; his sequuntur quinque series fossarum contiguarum quadratarum profunde impressarum. Margo tenue reflexus, postice rotundatus.

Corpus infra et pedes u. in reliquis.

IIab. in Songoria. D. Karelin.

\section{NEBRia Latreil.te.}

CARABUS $F$. Alpcus Bonell.

JS. Nebra splendida.

N. viridi-et cceruleo-cenea, splendida; thorace cordato, elytris angustiore; olytris subparallelis, lineatis, lineis clcvatis punctisque impressis triplici serie.

$$
\text { Long. } 8 \text { lin. Lat. } 2 \% \text { lin. }
$$

Nebria splendeda Fischer, Cat. Col. Fiarel. p. 5. n. 20.

Caput aneum splendidum, impressionibus fron- 
talibus duabus parallelis, antemis; ocnlisque nigris.

Thorax cordatus canaliculatus, antice posticeque transversaliter impressus; subemarginatus, marginibus limbatis, latere lato marginatus angulis posticis parum productis. Scuteilum triangulare basi dilatatum. Prosternum acuninatum valde abbreviatum.

Elytra thorace vix latiora lineata, lineis elevatis, quarta, sexta, octara punclis quatuor impressis interrupta, marginibus tenuibus reflexis. Corpus infra et pedes nigri, griseo-pilosi.

llab. in Songoria. D. Karelin.

\section{Nebria cxarata.}

N. fusca, parum nitens; thorace cordato dilatato nitido; elytris oblongo-ovatis punctis impressis irregularibus rugosa.

Long. 6 $\%$ lin. Lat. 3 lin.

Caput nigrum nitidun, impressionibus, frontali trausversa, lateralibusque profundis obliquis. Thorax cordatus dilatatus, latitudine fere elytrorum, profunde canaliculatus, latere late marginatus, limbo tenui reverso, angulis posticis productis. Scutellum triangulare brevissimum. Prosternum elevatum, basi intumidum, apice truncatum.

Elytra oblongo-ovata, postice subacuminata, 
punctis crebris irregularibus impressis exarata et rugosa. Nargines parum rellexi.

Corpus et pedes nigri parum nitentes.

Hab. in Rossia meridionali. D. Kindermans.

\section{Nebria Wiedemanni.}

1. nigro-fusca, parum nitens thorace cordato dilatato; elytris oblongo-oratis, lineatis, lineis omnibus punctis impressis indistincte notatis; antennis crassioribus, articulis apicis longe pilosis.

\section{Long. 7 lin. Lat. 2 \% lin.}

Capulnigrum, piceum, impressionibus frontalibus, antice punctis impressis rugosum. Palpi picei tenues. Antenna vulgo crassiores nigrae, articulo primo permagno cylindrico, reliquis obconicis, articulatione pilis longis obsitis, articulis ultimis lanie grisea tectis.

'Thorax cordatus, cum impressionibus vulgaribus; margines laterales cjus late reversi angulis posticis parum productis. Scutellum breve conicum medio sulcatum. Prosternum hasi valde elevatum, apice emarginatum.

Elytra thorace vix Jationa lineata, lineis elevatis, ommibus punclis quibusdam raris hinc illine notalis. Margines laterales tenue reflexi.

Corpus et pedes nigrri picei.

IJab. in Anatolia. D. Wedmans. 


\section{CI!I A T VIUS BOYEILI.}

IIARPALUS Gyll. CARABUS $F$.

\section{Chlonius angustatus.}

Chl. niger; thorace elongato-angustato, sublyrato; elyeris sulcatis; antennis pedibusque nigris.

Long. 4 lin. Lat. 2 lin.

Forma ad. Chl. corulem Struexr et Sterenii Schoenherr accedit, ast magnitudine el labitu interrinedius est.

Caput nigrum viriti-nitens, oculis griseis.

'Thorax subquadratus, elongatus, canaliculatus, marginibus tenue reflexis, postice impressionibus profundis triangularibus.

Corpus et pedes nigri picei, graciles.

Mab. in Turcomania. D. KaRFurN.

\section{Chlmius coxalis.}

Chl. capite thoraceque riridi-reneus; olytris subnigris opacis sulcatis; antennis pelibusque Jlaris, coxis posticis longissimis.

$$
\text { Jong. } 6 \text { lun. Lat. } 3 \text { lin. }
$$

Caput viridi-meum splendens, oculis nigris; antennis palpisque flavis.

'Thorax subquadratus, nitidus, candiculatus, latere parum marginatus, impressionibus posticis conicis profundis. 
Elytra glauca aut subnigra, opaca, lineata, lineis parum elevatis, marginibus parum reflexis coeruleis.

Corpus nigrum piceum. Peles ferruginei, coxis posticis longissimis.

IIab. in Georgia.

\title{
PRistonyCuUS Dejean.
}

\author{
Sphodrus, Bonelli.
}

\section{Pristonychus amcenus.}

P. apterus, cyaneus; thorace cordato postice profunde impresso; elytris oblongo-ovatis, subconrexis, striolatis, striis lavibus; tibiis intermediis rectis.

Long. 7 lin. Lat. $3 \%$ lin.

Pr. venusto similis videtur, sed clegantia forme striisque elytrorum simplicibus aut lavibus ab eo differt.

Caput elongatum nigrum splendidum, antennis palpisque nigris. Oculi magni planulati nigri.

'Thorax elongato-cordatus, profunde canaliculatus posticeque impressus, marginibus late reflexis, postice angulis productis.

Elytra oblongo-ovata, basi profunde et late cmarginata, striata, striis inpressis lexibus, interstitia elevata planulata hinc illine striis transversis notalia. 
Corpus nigrum piceum; pedes ejustem coloris. Mab. in Rossia meridionali. D. Kandruan.

\section{ACINOPUS Ziegler.}

Carabus Duftschmidt; IIarpalus Sturm; Scarites Olivier.

24. Acriopus cljpealus.

A. subcylindricus, ater, nitens; thorace quadrato; el)tris lavibus apice striatis; clypeo magno producto, apice rotundato.

Long. $6 \%$ lin. Lat. 3 lin.

Nagnitudine A. megacephali. Caput thorace paulo angustius, glabrum, nigrum nitilum antice irregulatiter impressum. Oculi magni globosi prominentes nigri. Clypeus magnus productus, antice rotundatus tribusque plicis indistinctis notatus, mandibulas fere totas tegens.

Thorax subquadratus postice paulo angustatus et impressionibus lateralibus, supra canaliculatus, latere submarginatus.

Elytra parallela glabra nitentia, apice distincte tenue striata.

llab. prope mare Caspium. D. Kareun.

25. Acinopus rufitarsis.

A. elongatus, parallelus, niger subnitidus; Lhorace subtransverso; el ytris striatis; antennarum articulo primo tarsisque ferrugineis. 
Long. 8 lin. Jat. 3 lin.

Caput postice angustatum inter antemnas profunde impressum; antice impressione subquadrata. Clypeus subquadratus, antice parum emarginatus. Antenux primo articulo ferrugineo, reliquis palpisque nigris.

'Thorax subtransversus longitudine latior, postice canaliculatus et utrinque impressus. Canalis non nisi posticam thoracis partem penetrat. Margo nuimque tenue limbatus.

Elytra profunde sulcata.

Pedes nigri, tarsis ferrugineis.

Hab. in Rossia meridionali.

26. Acropus spinipes.

A. latus depressus; thorace transverso; elytris striatis; tibiis omnibus ralde spinosis, intermediis incurvis.

Long. 10 lin. Lat. 5. lin.

Magnitudine A. Ammophili Sterex, sed thora. ce transverso, latere parum reflexo, striis elytrorum simplicibus alisque characteribus differre videtur.

Caput magnum productum, antice subrugosmm, cypeo magno lato, subemarginato, matrine rufociliato. Oculi albi. Antenua articulo prino nigro, reliquis piceis s. subferrugineis.

'Thorax transversus limbis levibus, in Ammo- 
philo distincte marginatus; margine lato dilatato, postice rotundato, subcanaliculatus, latere parum arcuatus.

Elytra parallela, striata, striis elegantibus simplicibus octo.

Corpus nigrum, piceum, nitidum.

Pedes nigri, tarsis piceis s. ferrugineis, tibiis setosis vel spinosis, intermediis incurvis.

llab. in Rossia meridionali.

* malacodermata.

\section{PODABRUS FISCHER.}

CANTIIARIS Linnaci.

27. Podabrus nigriventris.

P. clongatus, angustatus; capite thorace pedibusque flavis, ancennis, oculis abdomineque nigris. Long. 3 lin. Lat. 1 lin.

Caput flavescens, nutans, oculis nigris; antenna corporis longitudine, articulis primis quatuor flavis, reliquis nigris.

Thorax flavus, marginatus, antice punctis duabus fuscis obliquis notatus, medio convexus, postice transversin impressus.

Elytra parallela flavo-grisea opaca, impressione axillari utringue.

Corpus nigrum. Ablominis articulationes supra $N^{\circ}$ I. 1844 . 
punctis flavis angularibus notati. Pedes flavescentes.

Hab. Volhyniæ. D. Besser.

28. Podabrus vittatus.

P. elongatus, angustatus; capite thoraceque flavis; clytra fusco-grisea, flavo-limbata, vittata, vittis binis obscuris nigrescentibus, altera media, altera marginali.

Long. 3 lin. Lat, 1 lin.

Forma et habitus præcedentis. Caput nutans flavescens, oculis prominentibus nigris.

Thorax submarginatus flavus impressione postica triangulari profunda.

Elytra obscure grisea, albo marginata, vittis binis obscuris nigrescentibus, altera medio, alteraque margine.

Pectus nigrum, abdomen et pedes llavi.

Hab. in 'Tataria magna. D. PAnder.

29. Podabrus lunulatus.

P. flavo-fuscus; thorace marginato nitido, medio nigro-maculato; elytris pallidis, lunula apicis nigra.

Long. $4 \%$ lin. Lat. $1 \%$ lin.

Caput nutans fuscum, oris partibus pallidiori- 
bus. Antenna basi nigra, medio pallida, apice fusce.

Thorax marginatus fuscus splendidus, maculis linearibus duabus obliquis nigris medio.

Elytra pallide fusca, subpunctulata, apice nigrocincta sive Junula nigra terminata.

Corpus pallidum. Pedes pallide flav .

Hab. in Rossia meridionali. D. Boschnтак.

\section{Podabrus flavipes.}

P. angुustatus fuscus, splendidus; thorace suborbiculari; elytris subpilosis, pedibus ferrugineis. Magnitudine procedentis.

Podabrus flavipes Fiscuer Cat. Col. Karel. p. 8. n. 53 *

Societati unicum misit individuum e Songoria Cl. Karelin.

Ceratistes; nov. gen.

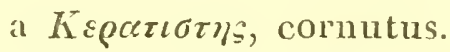

Antennce inxquales, serxato-setacex, primis quinque articulis crassioribus, hoc vel alio articulo valde dilatato, hamato.

Palpi acuminati.

Mandibulce breves, acutx, dentate.

Glypeus latus, transversus, bicarinatus, antice emarginatus.

Mentum valde dilatatum, antice emarginatum; cum clypeo partes oris arctissime constringens. 
Caput dilatatum, thorace latius, oculis magnis prominentibus; frons distincte cornuta, ant subtuberculata, cum facie geniculata, sive angulum. faciens, Cicindelarum ad instar. Antenna distantes sub quarum insertione impressio triangularis plerumque alius coloris, partem clypei superioris constituens. 'Thorax rotundatus, latere marginatus, postice angustatus.

Elytra thorace latiora parallela, apice acuminata, corpore maris breviora.

Pedes longissimi, postici corpore totius animalis longiores.

Femina fronte plerumque mutila antemnisque simplicioribus.

31. Ceratistes cornulus.

C. viridi-ceneus; thorace flavo-marginato; ore elytrorumque apice flavis; fronte maris cornuta.

Long. 2 lin. Lat. 1 lin.

Malachius cornutus Steven; Fischer Mas. Universit. II. Ins. Steveniana. P. 42.

Dejean, Catal. éd. 3. p. 122.

Species elegans et observatione digna, propter formam angustatam, maris fiontem cornutam et formationem antennarum singularem.

Caput mutans aut potius geniculatum, vertice dilatato viridi-seneo, oculis magnis prominentibus 


\section{7}

fuscis. Frons levis splendens medio cornu conico obtuso munita. Os et partes oris flave. Antemm nigre nitidx, articulis primis crassioribus serratis, quinto ita dilatato, ut hamatus aut cornutus adpareat; relicui obconici, setacei, Janugine grisea tecti.

Thorax rotundatus viridi-æneus splendens, flavo tenue marginatus. Elytra thorace latiora viridi-anea opaca subpunctulata, apice flavo. Corpus viridiæneum splendens. Pedes longissimi, femoribus æneoviridi-splendentibus, tarsis flavis.

Femina conveuit colore cum mari, exceptis fronte et antennis inermibus.

Hab. in Tauria; Cel. Steven; in Sibiria Cl. Gebler.

32. Ceratistes bipustulatus.

C. totus viridi-cencus, fronte subtuberculata; elytrorum apice flavo.

Magnitudine et forma præecedentis.

Malachius bipustulatus, Fabr. Syst. Eleuth. 1. 306. 4.

Grlenilal, lins. suec. 1. 358 . 9

Ilab. in Tauria, in Sibiria.

\section{MALTHINUS LatreILLE}

\section{CANTIARIS, L. Habr.}

33. Malthines aquestris.

M. parallelus; capile thoraceque viridi-ceneis; eljtris rufis, fascia et apice nigrescenti-ceneis. 


\section{8 \\ Long $2 \%$ lin. Lat. 3 lin.}

Malachius equestris, Victor Motschusk in literis.

Magnitudine M. biguttati Mannerherm, caput vero et thorax latitudinis æqualis, viridi-æneum. Thorax quadratus, pulvinatus, latere paullo extensus.

: Hab. in Tauria, D. Motschulsky.

\section{DASYTES FABR.}

MALYRis. Olivier,

\section{Dasites analis.}

D. niger splendidus; thorace pulvinato vix villoso, eljtris nigris, punctato-rugosis, pilis raris adspersis, margine apiceque ferrugineis.

Long. 2 lin. Lat. $1 \%$ lin.

Dasytes marginatus, Fischer, Cat. Col. Karel. p. 9. n. 55*

Nomen mutavi propter Das. marginatum Uldrich, (Dejear Cat. p. 125. Stury. Cat. p. 82 ) quem non vidi, quem tamen diversum a nostro suspicor.

Caput declive nigrum. 'Thorax pulvinatus, postice dilatatus, et transversim impressus, niger splendidus, brevissime aut vix hirsutus.

Elytra thoracis latitudine, nigra, subpubescentia, punctato-rugosa, sutura limbo elevato glabro, marginibus tenue apiceque late ferrugineis. 
Corpus nigrum piceum. Pedes pallidi.

Hab. in Songoria. D. Karelrn.

\section{'TRICHODES HERBST.}

\section{CLERUS, Latreille.}

35. Trichodes axillaris.

T. cceruleus; capite thoraceque griseo-pilosus; clytris punctatis, margine axillari et laterali ad dimidium usque guttisque apicis coccineis.

Long. 5 lin. Lat. 2. lin.

Trichodes axillaris, Fiscner. Cat. Col. Karel. p. 9. 11. 56.

Magnitudine T. illustris Steven aut punctati Dejean.

Caput et thorax profunde coerulea pilis densis et longis obsita. Antennæ, oculi palpique nigri.

Elytra punctato-subrugulosa nitentia, læte coerulea, margine axillari et laterali usque ad medium elytri ubi in fasciam dimidiatam desinit et gutta quadrangulari utrinque coccineis.

Pectus et corpus subcoerulea ænea.

Pedes coerulei.

Tr. punctatus puncta in medio et in apice coccinea habet; margo ejus coloris expers est. Puncti loco in $T r$. axillari fascia abbreviata adest.

Hab. in Songoria. D. Karelin. 


\section{CLAVICORNES. \\ NEGROPHORUS FABR.}

SILPIIA $L$.

36. Necrophorus limaties.

$N$, niger; thorace pulvinato, marginato; elytris nigris subcostatis, fascia semilunari coccinea, antennarumque capitulo flavescente.

\section{Long. 8 lin. Lat. 5 lin.}

Necrophorus lunatus, Fiscurn Cat. Col. Karel. p. 9. 11. 59.

Necrophoro Vespillone paullo minor.

Caput magnum exsertum nigrum, impressionibus lateralibus linearibus obliquis. Antennx nigræ, clava magna ovata, capitulo piloso pallide flavo.

Thorax latere late marginatus, postice rotundatus, medio supra convexus et antice lineis duabus impressis angulo cum semicanali mediano, forma $Y$, sese conjungentibus.

Elytra oblonga, parum convexa, nigra, subnilida, medio fascia lata semilumari coccinea, postice truncala.

Corpus nigrum piceun. Pedes ejusdesn coloris. Hab. in Songoria. D. Karelin 
Ciriterarcha, Schukati

NITIDULA Fabr.

37. Cryptarcha strigata.

C. fusca; thorace pulvinato, (*) margine flavolimbato; clytris margine, lunula baseos, fasciaque obliqua apicis flavescentibus.

Long. 2 lin. Lat. 1 lin.

Cryptarcha strigata, Sturm Cat. p. 46.

Nitidula-strigata, Olivier Ins. II. Pl. 2 f. $\%$

Nitidula strigata Farr. Elenth. I. 350 n. 12.

Panzer, Faun. germ. 83. 4.

Strongylus strigatus, Henest, Col. IV. t. 47 f. 7.

PaYkul, Faun. suec. I. 315 p. 12.

Hab. in 'Tauria, Curonia.

38. Cruptarcha sulcata.

C. tota nigra; thorace pulvinato, punctulato; elytris obsolete sulcatis.

Long. 2 lin. Lat. $1 \%$ lin.

Capul declive magnum.

Thorax transversus, punctulatus, convexus, tenuissime punclatum.

(*) Thorax pulvinatus, terminus Gyllenhalii, designaus thoracem ubique declivem. 
Elytra nigro-fusca, opaca, obscure sulcata, limbo tenui flavescente.

Corpus nigrum piceum. Pedes anteriores nigri, postici pallidi.

Hab. in Rossia meridionali (Sarepta.) D. KrwDERMANN.

\title{
* LANELlicorNeS.
}

\author{
ONITIS Latreille.
}

39. Onitis Sophax.

O. niger; thorace valde dilatato, punctulato; eljtris fuscis costatis, costis tribus valde clevatis, incrassatis.

$$
\text { Long. } 10 \text { lin. Lat. } 5 \% \text { lin. }
$$

Proportio particm:

$\begin{array}{lccc} & \text { capitis, } & \text { thoracis, } & \text { clytrorum. } \\ \text { Long. } & 2 & 4 & 5 \\ \text { Lat. } & 2 \% / 2 & 5 & 5 \%\end{array}$

Forma thoracis ad Damotam, elytrorum ad Amyntam accedit.

Caput nutans nigrum, fronte transversa, nodulis elevatis sex, medio punctis impressis rugosum. Clypeus magnus extensus subsexangularis, antice limbo tenui reflexo.

Thorax magnus pulvinatus, punctato-rugosus, niger, postice rotundatus impressionibus duabus 
vulgaribus, latere rotundatus limbo tenui reflexo.

Elytra latere subsinuata, supra costata, costis tribus incrassatis elevatis, subincurvis, una suturali, altera mediana, tertia marginali. Basis elytrorum initio costarum incompletarum crenulata, apex eorum vestigio costarum distincto. Spatium intermedium inter costam suturalem et medianam punctis impressis scabrum, prope suturalem series punctorum elevatorum; spatium intermarginale costis minus elevatis et punctis impressis repletum.

Corpus nigrum opacum. Pedes fortissimi nigri nitidi; femora intermediorum quam maxime dilatata, posticorum subincurva, planulata, punctis impressis obsita, basi spinis utrimque longissimis munita, latere interno lamina compressa linea impressa distincta, spinis donata.

Hab. in Sibiria orientali. D. Karelin.

\section{onthophaguS Latreille.}

\section{COpRIS Fabr.}

40. Onthophagus tricornis.

O. thorace ceneo-cupreo, antice emarginato; occipi-te trispinoso, spina media longa erecta, lateralibus, brevioribus, obtusis; elytris pallido fuscis, obsolcte sulcatis, nigro punctatis. 
Magnitudine O. nutantis Fabr.

Caput magnum nigro-acneum, clypeo magno medio tuberculo elevato, antice margine reflexo, occipite nitente lamina elevata tres spinas gerente, media longa erecta, basi fortiori, lateralibus brevioribus, obtusis. Partes oris ciliis longis ferrugineis obsitæ.

Thorax cupro-aneus, pulvinatus, subtilissime punctulatus, latere marginato, medio nodulo parvo, antice profunde et late emarginato.

Elytra pallide ferruginea, striata s. sulcata, sulcis obtusis deplanata, punctis s. maculis nigris seriatim adspersis. Corpus nigrum piceum. Pedes nigri nitidi. Prosternum lineis duabus elevatis medio; mesosternum valde dilatatum, utrimque lineis elevatis temuioribus.

Femina thorace subtuberculato, tuberculis duabus parum elevatis; occipite lamina elevata, medio emarginata, angulis elevatis acuminatis.

Hab. in Rossia meridionali. D. Zwick.

\section{Oxthophages specularis.}

O. thorace aneo bituberculato; occipite cylindrice cxcavato, speculari; cljpeo lato sulconico, margine antico valde reflexo; elytris substriatis, pallide ferrugineis, punctis quibusdam nigris. 


\title{
45
}

Long. 6 lin. Lat. 3 lin.

Mare caremus ad speciem rite difiniendam. Hab. in Caucaso.

aphODIUS, Tlliger, Fabr.

\author{
SCARABAEUS $L$.
}

42. Aplopius hirtipes.

A. niger nitidus; capite unituberculato; thorace transverso convexo; elytris sulcatis, postice setis brevibus hirtis; tibiis omnibus utrinque pilosis.

Long. 3 lin. Lat. 1 lin.

Magnitudine Aphodii conspurcati $\boldsymbol{F}$.

Caput crassum nigrum nitidum, tuberculo frontali, clypeo subemarginato.

Thorax transversus, æneo-niger, nitidus, latere tenue marginatus.

Elytra fusca, sulcata, sulcis profundis simplicibus, apice setosa.

Corpus nigrum nitidum. Pedes nigri, tibiis omnibus utrinque setis longis hirtis.

Ilab. in Rossia meridionali. Ekatherinengrad. D. Haupt.

43. Apiodius gonagricus.

A. niger nitidus capite mutico, thorace transverso convexo slabro; elytris pallidis sulcatis, 
sulcis simplicibus; tibiis posticis externe tuberculatis.

Long. 4 lin. Lat. 2 lin.

Magnitudine Aph. fimetarii $\mathrm{F}$, capite paullo magis abbreviato.

Caput nigrum nitidum muticum clypeo extenso antice margine reflexo.

'Thorax transversus convexus, subtilissime punctulatus, marginibus paullo magis dilatato-reflexis. Elytra abdomine breviora, pallida, sulcata, sulcis binis posticis nigrescentibus.

Corpus nigrum nitidum. Pedes ejusdem coloris tibiis posticis subincurvis, latere externo trituberculatis.

Hab. in Dauria.

\section{CYPHONOTUS FIscher.}

MELOLONTHA Fabr. CATALASIS Dejean.

Genus propositum in Entomographia rossica. II. 215. 1823.

Hodie acceptum, mutato nomine Catalasis ab illustr. Comite Dejean, Cat. ed. 3. 1837. p. 176. et a Cl. Stura, Cat. 1843. p. 121.

44. Cyphonotus Anketeri s. testaceus.

C. clongatus cylindricus convexus punctulatus, totus fuscus, commissura thoracis pallidevillosa. 
Long. 1 poll. 4 lin. Lat. 5 lin

Entomographic de la Russic. II. 212, 213. tab. XXVIII. f. 4.

Cyphonotus testaceus, KRYsicki, Bull. de la Soc. I. 1829. p. 192.

Edit. gallica. (Bibliothèque entomologique) p. 57.

Melolontha Anketeri, Hersst Col. 1II. 43. 3. t 22. f. 4.

Nelolonthe pilosa varietas, Schönher, Syn. III. 176.

Scarabaeus testacens, Pallas, Ieon. p. 19. t. B. f. 22.

Caput magnum clypeo majori reflexo, supra punctulato, infra piloso, apice emarginato. Antennæ facie postica pilosx. Palpi articulis primis pilosis, ultimo nudo.

Thorax subquadratus pulvinatus tenue marginatus, medio supra impressione lineari transversa, postice subemarginatus, albo-s. flavo-ciliatus. Scutellum magnum subconicum, apice rotundatum, medio canaliculatum.

Elytra convexa punctulata, postice seorsim rotundata, abdomine breviora.

Corpus fuscum, setis raris obsitum. Facies superior abdominis dense albo-villosum. Pedes fortes nigro-fusci, tibiis omnibus externe tridentatis. Tarsi longissimi, articulis omnibus utrinque setosis, ultimo unguicali longiori, nudo, unguibus debilibus.

Hab. in Caucaso.

45. Cyphonotus Monachlus.

C. fuscus; thorace transverso pulvinato punctulato 
nitido, ubique pilis longis albis cinctis; elytris fuscis opacis, punctulatis, basi distincte, supra obliterate sulcatis.

\section{Long. 17 lin. Lat. 4 lin.}

Cyphonotus Monachus, Krynick , Bull. I. c. p. 192. ed. gall. p. 17.

Caput parvum fuscum punctulatum opacum, clypeo abbreviato rellexo, non emarginato. Oculi nigri. Partes oris fusce, non pilosæ.

'Thorax transversus convexus, tenue punctulatus, latere antice posticeque pilis longis albis cinctus. Scutellum forma pracedentis sed quadrisulcatum.

Elytra pallide ferruginea opaca, tenuissime punctulata, basi distincte supra obliterate sulcata.

Corpus nigro-fuscum opacum. Pedes ferruginei splendidi, tibiis anticis tridentatis, intermediis spinosis, posticis subcylindricis, apice dilatatis, excavatis, spinis duabus longis et fortibus.

Hab. in 'Turcomania.' D. Karelin.

16. Cyphonotus thoracicus.

C. ferrugineus opacus; capite late-marginato; thorace pulvinato punctulato, dorso fossulis tribus transversim profunde impressis; elytris punctatis, obliterate sulcatis. 
Cyphonotus thoracicns, (*) Lingricks Bull. 1. c. P. 192. Eil. gall. p. 58.

Caput breve, tenue punctulatum, clypeo lato rotundato reflexo.

Thorax transversus, pulvinatus, punctulatus, foveis tribus dorsalibus impressis, transversim locatis. Scutcllum conicum, basi valde dilatatum, apice acutum. Pectus ferrugineo pilosum.

Elytra, corpus, pedes forma pracedentis conveniunt.

Hab. in Rossia meridionali. Sarepta. D. Zwıск.

47. Сурнолотus macrophyllus.

C. fuscus, capite margine punctatum; thorace transrerso subconsexo, ciliis albis cincto; elytris punctulatis obliterate sulcatis; antennarum copitulo longiori compresso.

$$
\text { Long. } 7 \text { lin. Lat. } 4 \text { lin. }
$$

Caput transversum latum breve, punctulato-rugosum, clypeo rotundato late reflexo. Oculi nigri. Antennæ pallidæ, capitulo compresso vulgo longiori.

Thorax transversus convexus splendens, subtilissime punctulatus. Loco canalis dorsalis linea lævis nitida. Pectus longe albo-pilosum.

$\left(^{*}\right.$ Cyphonotum thoracicum et Monachum $\mathrm{Cl}^{\circ}$ linxwick l hisec nominibus communicavi.

$N^{\circ}$ I. 1844. 
Elytra pallidiora, punctulata, obliterate sulcata.

Corpus fuscunı opacum, lanugine fusca obsitum, ano nigro. .

Hab. in Turcomania. D. Karelin.

48. Cyphonotus a.finis.

C. fuscus; capite magno opaco punctatim rugoso; thorace transserso consexo, canaliculato; elytris distincte sulcatis seriatimque punctatis.

Long. 7 lin. Lat. 4 lin.

Magnitudine precedentis, quocum magnam offert affinitatem. Sed thorax distincte canaliculatus et elytra sulcata et seriatim punctata enm facile distinguunt.

Caput valde dilatatum, clypeo lato reflexo, subemarginato. Capitulum antennx eque compressum accedit magnitudini praecedentis.

Thorax distincte canaliculatus, totus pilosus, marginibus ferrugineo ciliatis. Foveæ obliterate adparent quatuor transversim locatæ.

Pectus longe pilosum.

Elytra distincte sulcata, medio seriatim punctata, latere punctis crebris rugosa.

Corpus fuscum opacum. Pedes pallidiores, femoribus et tibis punctatis, punctis impressis.

llub. ibidem cum precedente. 


\section{1}

Nota. Cl. Krynicki Melolontham farinosam lisenscrourz omni jure ad genns Cyphonoti traxit.

Bull. 3. c. p. 192. Ed. gall. p. 57.

\section{CETONIA Fabr.}

49. Cetonia proctotricha.

C. viridi-coneo-nitens; supra tota viridi-smaragdina; ano longe albo-setoso.

$$
\text { Long. } 10 \% \text {, lin. Lat. } 6 \mathrm{Iin} \text {. }
$$

Cetonia Proctotricha, Fiscuer, Cat. Col. Karel. p. 13.

Caput prolongatum, punctulatum, medio cavernosum, antice angustatum, clypeo reflexo, oculis nigris.

Thorax dilatatus elongatus subtriangularis, subtilissime punctulatus parum convexus, antice emarginatus, postice rotundatus. Scutellum triangulare longum acutum.

Elytra dense et profunde punctata, marginibus subciliatis.

Corpus viridi-æneum nitidum, pectore longe piloso, pilis ferragineis.

Lamina inferior analis setis longis obsita. Pedes viridi-ænei femoribus anticis et intermediis longe albo-pilosis.

Hab. in Songoria. D. Karelin. 
50. Cetonia fasciata.

C. cupreo-cenea, infra nitida, supra opaca; thorace albo limbato; clytris punctatis, fasciis geniculatis interruptis albis.

Long. 10 lin. Lat. $7 \mathrm{lin}$.

Magnitudine fere præecelentis ita ut eam pro varietate adultiore habuerim, nisi basis elytrorum magis dilatata, corpus inferius nitens et pilosum, denique delineatio elytrorum me de contrario convicerint.

Caput xneum nitidum, profunde punctulatum, antice magis dilatatum, clypeo reflexo emarginato.

Thorax aneus opacus profunde sed rarius punctulatus, forme vulgaris, latere albo marginato. Color hic sub lente pilis lavibus albis constitutus videtur.

Elytra anea opaca punctata, basi dilatata, sinu laterali albo cincto, apice fasciis binis geniculatis interruptis albis.

Corpus aneum nitidum. Pectus subpilosum, prosterno obtuso, metasternum medio sulcato, sulco lato profundo.

Pedes anei splendidi, femoribus intermediis et mesosterno longe pilosis.

Hab. in Songoria. D. Karelin. 


\title{
II. H ETEROMERA.
}

\section{* MELANOSOMa'Ta.}

\author{
PINELIA Fabr.
}

51. Phela marginala.

P. nigra, thorace transverso punctulato; elytris oblongo-ovatis granulatis, granulis seriatim dispositis.

Long. $7 \%$ lin. Lat. $4 \%$ lin.

Caput magnum punctatum opacum, clypeo abbreviato antice subrotundato ciliato. Antennæ fortiores breviores.

Thorax transversus punctulatus opacus, antice emarginatus, albo-breviciliatus, marginatus, nırginibus tenue reflexis. Prostermun latum apice truncatum fossulatum.

Elytra oblongo-ovata, granulata, granulis planis subdistantibus regulariter seriatim dispositis. Margo subcrenulatus.

Corpus nigrum opacum glabrum.

Pedes graciles.

Hab. in Turcomania. D. Kareln. 


\section{P'TEROCOMA Solier.}

Pimelia Sarpa Fiscir. Solier Annal. V. 46.

PACHYSCELIS Solier.

52. Pachyscelis Karelini.

1. nigra; thorace transverso glabro nitido; elytris ovato-globosis granulatis, granulis irregulariter approximatis variolosis, marginibus crenulatis.

Long. 10 lin. Lat. 6 lin.

Caput exsertum glabrum, clypeo magno quadrato basi granulato. Antennæ articulo secundo vulgo longiore, sequentibus obconicis, ultimo globoso, acuminato.

Thorax transversus glaber, antice parum emarginatus; ciliis ferrugineis donatus. Prosternum basi dilatatum, linea undulata impressa, apice truncatum, emarginatum.

Elytra ovato-globosa, granulosa, granulis elevatis irregulariter et dense coarctatis variolosa. Sutura elevata lavis. Margines laterales crenulati, late amplectentes abdomen, limbo inferiori lato lævi.

Corpus nigrum opacum, granulis torulosum. Pedes omnes granulis horridi. Tibiæ anticæ late sulcatæ, apice valde dilatatie, exceptis spinis internis obtusis, adpendice extema longissima. Tarsi dila- 


\section{5}

tati utrinque spinosi, unguibus debilibus; postici angustiores longiores.

Hab. in Turcomania. D. Karetre.

\section{OCíERA , Fischer. \\ al) $0 \%$ regos, lentus, piger.}

Entomographic de la Russie 1. 169. 1822.

Trachyderma Lalrcille, Cuvier Règne anim. IV. p. 71829.

53. Ocnera lepidacantha.

O. nigra; thorace elongato-quadrato, subtilissime punctulato; elytris oblongo-ovatis granulatoscabris, granulis elevatis coarctatis squamatospinosis triplici serie.

$$
\text { Long. 10. lin. Lat. (6. lin. }
$$

Ocnera lepidacantha, Bull. II. 1830. p. 18\% edit. gall. p. 97.

Caput magnum subcruadratum opacum, clypeo quadrato a facie impressione disjuncto, nitido, impressionibus lateralibus obliquis aut medio elevato convexo. Antemne articulo tertio et quarto, facie interna setis sensim gradatimque longioribus munitis.

'Thorax quadratus convexus, latere medio rotundatus, submarginatus, subpunctatus opacus. Prosternum basi rotundatum, convexum, in conum longum obtusum productum. 
Elytra granulosa, granulis concinnis elevatis duplici serie, interstitiis excavatis granulato-scabris, marginibns crenulatis aut squamato-spinosis. Pars amplectens abdomen inferius lineam adhuc fert elevatam granulorum squamato-spinosorum. Limbus hujus partis est lævis lateque sulcatus.

Corpus subtilissime granulatum. Pedes debiles.

Hab. in Turcomania. D. Karelin.

\section{Ocnera granulata.}

O. nigra; thorace quadrato, granulato, marginibus lateralibus subrotundatis; elytris oblongo-oratis granulatis, granulis elcvatis concinnis seriatis, marginibus vix crenulatis.

Long. 10 lin. Lat. 5 lin.

Caput exsertum granulatum, clypeo antice rotundato, postice impressione lineari a facie sejuncto.

Thorax quadratus, marginibus subrotundatis, granulis parvis scaber. Prosternum latum convexum, apice truncatum emarginatum.

Elytra olslongo-ovata, gramulata, granulis parum elevalis, seriatim et anguste dispositis; margines laterales subcrennlati, mangines abdominales late sulcati.

Corpus subgranujosum opacum. Pedes graciles granulis horridi.

llab. in 'Turcomaniat. D. Kafents. 


\section{7}

\section{TRIGONOSCELIS Solter.}

Pimclia nodosa Fiscuer Ent. ross. I. 149. L. 14. f. 3.

\section{Trigonoscelis echinata.}

Tr. nigra; thorace quadrato, marginato, angulis anticis productis; elytris oblongo-ovatis, gुranulatis, marginibus spinosis.

Long. 9 lin. Lat. 4 lin.

Pimelia echinata, Karelin, in literis.

Magnitudine Tr. nodose, a qua differt forma thoracis et dispositione granulorum in elytris qua in nodosa distant inter se et seriebus distantibus locata sunt.

Caput maguum exsertum subquadratnm rugosum, clypeo angusto quadrato basi granulato, apice emarginato.

'Thorax quadratus punctulatus marginatus, marginibus tenue reflexis, antice in apicem productis. Prosternum latum in conum obtusum desinens.

Elytra oblonga ovala, granulata, granulis subseriatim dispositis, seriebus inequaliter alternantibus majoribus et minoribus. Margines laterales spinosi.

Corpus nigrum opacum.

Hab. in Turcomania. D. Karelix. 


\section{8}

\section{LASIOSTOLA Dejean.}

Hirta, Pimelia, Fiscuer Entom. ross. I. 152. Pl. XIV. f. 5. 56. Lasiostola heterogena.

L. suborbicularis, thorace quadrato granulato; elytris granulato-scabris.

Long. 6 lin. Lat. 3 lin.

Etsi antennæ, partes oris formaque corporis hujus speciei cum Lasiostolis conveniunt, defectus hirsutiei extraneus videtur, propterea quod heterogena nominata fuit.

Caput exsertum punctatum opacum, clypeo obtuse conico. Oculi globosi prominuli.

Thorax quadratus, latere parum marginatus, punctatus opacus. Prosternum rotundatum cono brevi terminatum.

Elytra subacuminata, postice declivia, tenuissime granulata.

Corpus nigrum opacum.

Hab. in Turcomania. D. Karelin.

ADESMIA Fischer.

Pimelia Fabr. Ilerbst.

Cf. Bulletin de la Soc. Vol. VIII. 1835 p. $310-316$. 'l. VIII. 


\section{PIATYOPE Fischer.}

Pimelia, $\Lambda$ kis Fabr. Teuebrio Pall.

Species rossicx hucusque cognita sunt sequentes:

\section{Puatyope granulata.}

Entomogr. ross. 1. 161. Pl. XV. f. 1.

Dejean, Cat. ed. 3. p. 199.

Sturm, Cat. ed. 1843. p. 142.

e Tartaria, Sibiria: Nor-Saisan.

\section{Platyope proctoleluca.}

Entomogr. ross. 1. 164. n. 3. t. XV. f. 3.

Dejean, Cat. cd. 3. p. 199.

e Sibiria: Bukhtarminck. - Nor-Saisan.

59. Platyope leucographa.

Entomogr. ross. I. 163. n. 2. t. XV. f. 2.

Tenebrio leucographlus, Pallas, Icon. 1. 54. t. C. f. 20.

Tenebrio lencogrammus, Paudas Iter App. 719. n. 43.

Dejean Cat. ed. 3. p. 199.

Sturs, Cat. ed. 1843. p. 142. Faun. german. 2. 195. t. 43.

Pimelia leucographa Fавп. Ent. syst. I. 105. 30

Herbst Coleopt. VIII. 103 56. t. 124. f. 4.

Panzer Faun. germ. 1. 38.2.

Linver Syst. ed. Gmelini IV. 2012. 83.

Akis leucographa, Faвr. System. Eleuth. I. 136.7.

ScnövuERr, Synon. I. 140. 14.

Nota. Platyope leucogramma Eschschol.tz a Cl. 
Sturm (Cat. p. 142.) teste Gebler, (Ledebour, Reise. II. 3. 116.) pro vera specie, ab Illustr. Com. Dejean (Cat. ed. 3. p. 199 ) pro varietate leucographce habetur. Equidem $\mathrm{Pl}$. leucogrammam marem esse $P l$.leucograpluce crediderim.

60. Platyope lineata.

Pimelia lineata FArr. Ent. syst. I. 105. 219.

Platyope dichotoma, Fisciner, Bullet. II. 1830. p. 18\%. ed. gall. p. $9 \%$.

Sepidium lineatum, Thunburg, Nov. spec. insect. 6. 18. n.16. Olivier, Ins. 51. Pl. 2. f. 20.

Hernst Coleopt. t. 124. f. 3.

Akis lineata, FAв. Syst. Eleuth. I. 136. 6.

IIab. Sibiriæ prope fluv. Irtysch.

\section{Platyope obliterata.}

Pl. thorace transverso, granulato-scabro; elytris granulatis, granulis magis elevatis duplici serie, lineis tomentosis abbreviatis albis apicalibus.

Long. 5 lin. Lat. 4 lin.

Caput inclinatum granulatum, fronte transversim impressa, clypeo nitente quadrato antice dilatato et paullo incurvo. Oculi parvi plani fusci. Antennæ graciles nigrescenti-nitentes, articulo primo longiore, nee crassiore reliquis.

Thorax transversus utrinque impressus, marginibus antice prominentilous, granulis elevatis sca- 
ber, sepius impressione medio profunda, (nisi accillentali)? Prosternum basi dilatatum, in conum subgranulatum obtusum desinens, apice emarginatum.

Elytra crebre et dense granulata, seriebus binis magis elevatis, lincis tribus abbreviatis albo-tomentosis apicalibus. Margines laterales crenulati. Pars amplectens abdomen lineas duas albo-tomentosas gerit, alteram angustiorem, alteram latiorem.

Corpus nigrum opacum tomento vix sensibili albo obductum. Pedes nigri nitidi, tibiis anticis apice valde dilatatis, margine externo multispinoso s. multidentato. Pedes postici reliquis longiores, tibiis simplicibus, tarsis valde dilatatis inferius longe setosis.

IIab. Sibirix prope lacum Inderskoe.

\section{Platyope, zunicolor.}

Platyope unicolor Eschischoltz Zovrkov, Bull. I. 1829. p. 150. t. 19. f. 7 .

Dejean, Cat. ed. 3. p. 199.

Stura, Cat. ed. 1843. p. 142.

Platyope Karelini, Kirsnick1, Bull. 1. с. p. 193. n. 21. (ed. gall. p. 58 ).

Cl. Krynicki observationem addit: "Olim pronova habui specie, sed nunc observatione amicissimi Karelinr persuasus, eam feminam Pl. leucographce esse agnosco. "Sive in olsservatione sive in ejus expressione error regnare videtur. Insectum multo minus Pl. leucographe non potest esse 
fenina ejus. Ceterum a Cl. Karelin marem leucographa accepi, minorem certe, sed lineis albo-tomentosis plus minusve distinctis femine similibus.

\section{Platyope collaris.}

Pl. nigra tota tomento levissimo albo adspersa; thorace transverso, granulis incequalibus aspro, profunde canaliculato; elytris granulatis, granulis elevatis triplici serie, marginibus subcrenulatis, reflexis.

\section{Long. 5 lin. Lat. $3 \%$ lin.}

Species unica quæ canali thoracis dorsali aut potius fossa profunda sese distinguit.

Caput vix granulatum, opacum. Antennæ crassiores, articulo primo magis incrassato. Palpi geniculati, ultimo articulo elongato-ovato acuminato.

Thorax transversus valde rugosus dorso fossa, loco canalis, impressus. Margines anticus et laterales nigri nitidi, posticus declivis. Prosternum basi latum, cono plano, truncato terminatum.

Elytra plus acuminata apice reliquis, granulata, granulis elevatis triplici serie. Margines subcrenulati, subreflexi aut potius subdilatati. Pars amplectens abdomen, granulata, costata, costis tribus subelevatis, planulatis.

Pedes debiles, similes iis obliteratce, tibiis anticis subincuvis, dictincte sexdentatis.

Hab. in Songoria. D. Karer.tN. 


\section{3}

\section{DIESIA Frscher.}

Entom. rossica. I. 166- 169. Pl. XIV.

\section{Diesia Karelini.}

D. nigra, opaca; thorace quadrato convexo, marginato; elytris marginatis granulatis; tibiis anticis octo-dentatis.

\section{Long. 9 lin. Lat. 5 lin.}

Forma et sculptura elegantissima species majorque reliquis cognitis. Caput magnum convexum punctulatum nutans, epistomate angustato antice acuminato, Jabro magno splendido, antice dilatato, recta truncato, subintumido.

Thorax quadratus, convexus, punctulatus, latere limbatus, antice posticeque leviter sinuatus, ferrugineo ciliatus. Scutellum magnum, triangulare, rude.

Elytra parallela, inferius abdomen late amplectentia, facie ista prope marginem granulata, medio costata, costa lævi; facies superior granulata, granulis elevatioribus duplici serie, sutura impressa; latere marginata, margine elevato, granulato.

Corpus opacum subpulverulentum. Pedes graciles; antici prosterno magno, medio sulcato, apice elevato, acuminato, sejuncti; tibic octo-ad decemdentatæ s. spinosac. Tarsi gracillimi, ultimo articu- 
lo subnodoso, unguibus longis, tenuibus, distantibus.

Hab. in Turcomania. D. Karelin.

TENTYRIA Latreille.

\section{Tentyria Kindermanni.}

T. consexa, ovata, nilida; thorace orbiculato, glabro; elytris elongato-ovatis sulcatis, sulcis longitudinalibus et transversalibus unclulatis sese decussantibus.

Long. 7 lin. Lat. $3 \frac{1}{2}$ lin.

Caput magnum, exsertum, vertice nitido, epistomate transverso, labro brevi, antice rotundato. Antennæ articulis inæqualibus, articulo primo crasso longo cylindrico, secundo abbreviato obconico, tertio longitudine priorum. utrorumque, cylindrico, reliquis obconicis longitudine subæqualibus; ultimi tres globosi.

Thorax orbicularis convexus glaber nitidus, fovea rotunda postice impressus.

Elytra elongato-ovata splendida, sulcata, sulcis impressis undulatis longitudinalibus et transversalibus; sulci longitudinales versus apicem in series, punctorum impressorum abeunt.

Corpus subnitidum. Pedes fortes. Prosternum dilitatum leviter sulcatum.

Hab. in Rossia meridionali; prope Sarpam. D. KiNDERMaNx. 


\section{ANATOL.ICA Escuscuortz.}

Derticulata; sulciceps, Gebuer, Conf. Bull, 1811. Vol. XIV. p. $591-592$.

66. Anatolica torulosa.

A. Opaca; thorace quadrato; elytris ovatis, punctis latis seriatim impressis, torulosis.

$$
\text { Long. } 51 / 2 \text { lin. Lat. } 2 \% \text { lin. }
$$

Caput latum porrectum, epistomate foveolis impresso: labro lato apice rotundato.

Thorax transversus, antice paullo dilatatus, postice restrictus, punctulatus, sulco medio dorsali lato parum profundo impressus.

Elytra ovata, latere punctulata, medio punctis aut potius foveis bina serie impressis.

Corpus nitidum. Pedes graciles, opaci. Prosternum elevatum angustum, medio profunde sulcatum.

Ilab. in Dauria.

\section{Anatolica thoracica.}

A. depressa, splendida; thorace transverso, fossa dorsali, lata et profunda; elytris ovatis, dorso planis prope suturam costatis, latere declivibus punctulatis.

Long. 6 lin. Lat. $2 \%$, lin.

$$
\text { N. I. } 1844 .
$$


Caput latum nitidum, epistomate obliterato: labro quadrato, apice emarginato.

Thorax transversus, lateribus subparallelis, angulis posticis exsertis, acutis, medio fossa dorsali magna, levi, nitida.

Elytra ovata, subdepressa, costis suturalibus elevatis utrinque, latere declivia punctulata.

Corpus nitidum. Pedes fortes.

Prosternum dilatatum, apice elevatum, sulcatum.

Hab. in Bucharia.

68. Anatolica angulosa.

A. opaca, thorace transverso, antice posticeque angulis liberis; elytris ov'atis subpunctulatis nitidis.

Long. 4 lin. Lat. 2 lin.

Caput latum opacum, antice punctis duobus impressum; epistomate triangulari antice reflexo, intumido, labro quadrato brevi, antice ciliato.

Thorax transversus, convexus, punctulatus, opacus, angulis omnibus distinctis liberis. Fossula loco scutelli.

Elytra ovata, abbreviata, lævia nitida; subtilissime punctulata.

Corpus sericei-nitoris. Pedes debiles. Prosternum latum, sulcis linearibus utrinque.

Hab. in Sibiria, Nertschinsk. 
RHOSTAX. N. GEN.

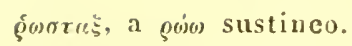

Ore porrecto.

Mentum subglobosum, convexum, nitidum, antice rotundatum, pedunculo quadrato insidens.

Palpi ultimo articulo obconico. Mandibula arcuatæ, basi fortes, apice subito acuminate.

Labrum transversum longum, protractum apice dilatatum intumidum, epistomate quadrato, angustato.

Antennæ-subfiliformes, externe paullo crassiores; articulo primo magno cylindrico, secundo brevi, tertio ad sextum subcylindricis, ultimis globosis, globulis sejunctis, ultimo obtuso.

Character forma residet in thorace globoso postice valde restricto, quasi peduuculato. Magnitudine et forma admodum accedit Anatolice macrocephalce Tauscheri, quam ad hoc genus retulerim, nisi thorax ejus globosus sessilis esset.

\section{Rhostax Karelini.}

R. elongatus, nitidus; thorace orbiculari convexo, postice longe restricto; clytris elongato-ovatis, glabris, nitidis.

Long. 4 lin. Lat. $1 \%$ lin.

Caput longum, protractum, punctulatum, opacum; labro magno scabro, nitido, latere sulcato, antice dilatato, margine tumido. 
'Thorax orbicularis, convexus, lævis, postice coarctatus, quasi pedunculatus, scutello minimo.

Elytra elongato-ovata, glabra, nitida, postice sensim in conum obtusum abeuntia.

Corpus subopacum. Pedes graciles, anteriores intermediis adproximati. Prosternum abbreviatum, obtusum.

Hab. in Songoria. D. Karelin.

\section{Rhostax Menetriesii.}

Rh. abbreviatus, nitidus; thorace globoso, postice breviter restricto; elytris abbreviatis, ovatis, glabris nitidis.

Long. 4 lin. Lat. $1 \%$ lin.

Anatolica elegans MÉNĖTriés in lit. n. 17.

Caput magnum exsertum glabrum, vertice transversim impresso; labro transverso, antice subemarginato.

'Thorax globosus, postice angustatus, nitidus.

Elytra ovata, abjoreviata, convexa nitida, sutura elevata.

Corpus subopacum. Pedes graciles, distantes inter se. Prosternum abbreviatum, elevatum apice et sulcatum.

Hab. in Rossia meridionali; prope mare Caspium. D. Karelin. 
GNAPTOR Fischer.

grextup a yvexten, rodere, ficare.

Tencbrio, Pallas. Sturm; Blaps Fabr.

71. Spinimaxus, Fischer Mus. Univers. mosquens. 1829 . I. p. 69.

Tenebrio spinimanus, Pallas icon. p. 53. Tab. C. f. 23.

Panzer, Faun. germ. 59. 1.

Blaps spinimana, Schönnerr, Syn. Ins. I. 1. p. 145. n. G.

Pimelia levigata, Farr. Syst. Eneuth. 1. 129. 5.

Pimelia glabrata, Hernst, Col. VIII. 56. n. 12. t. 120. f. 12.

Cochlodera spinimana, Escuscnoutz, in Collect.

Guaptor spinimanas Dejean, Cat. ed. 3. 208.

Falderanan, Faun. transcaucas. c. Mém. de la Soc. VI. 115.

Blaps spinipes, Far. Syst. Eleuth. I. 142. 5.

IIab, in Tauria.

Nota. Nescio quo casu nomen hujus generis a Cell. Dejeax, Sturit, Falderiani, Clo. Megerle tributum fuetit.

\section{BLAPS FABR.}

a Bhrexrev nocere. Vocabulum itaque Blaps, blaptis cum Fabricio nec Blaps, blapis, cum Illigero declinandum.

Tenebrio. $L$.

Blaptis genus etsi cognitissimum, speciebus tamen difficillime extricandum.

Corpus oblongum, convexum, robustum, marginatum, elytris connatis, abdomen infra ample 
ctentibus, postice sæpius adpendiculatis s. mucronatis.

Nec alæ, nec scutellum $\left(^{*}\right)$ nltimus articulus palporum maxillarium securiformis. Antennæe heterogenx, primis articulis septem obconicis, ultimis quatuor globosis.

Pedes fortes, femoribus compressis, inferius sulcatis.

Nocturna, in locis humidis, sub lapidibus plantisque putridis habitantia.

Character externus vix sexum divinari sinit. Mucro elytrorum longus aut abbreviatus ntrique sexui proprius est. Femina tamen lamina abdominis ultima majore, basi dilatatiori, cognosci potest. Nam fasciculus setarum ferruginearum, sub primo articulo abdominis, quem feminæ tribuunt, quibus, lapides aut corpora dura terendo, mares allicere contendunt, (Heinecken, Zool. Journ. 18. p. 200 ) raro adest. Videtur adpendix externa, qux cum partibus internis nullum habet nexum.

Si ad structuram et formam elytrorun, sæpius mucronibus plus minusve longis munitorum solam, respiciamus, copula horum animalium difficillime intelligeretur. Partes internæ quæstionem

$\left(^{\star}\right)$ Prisentia scutelli in unica specic primæ sectionis miln: obvenit. Sunt quæ constanter scutellum possidcant, ubi vero alii characteres novum genus, (ccrte subgenus Peltarii) creandinecessitatem imponerc videntur. 
propositam expediunt. Uterque sexus partes genitales possidet extensiles. Nas tubum longum, cylindricum, apice attenuatum ex abdomine exserere potest. 'Tubus iste capsula duplici sustentatur, quxe laminis binis basalibus, et mediis componitur. Laminæ basales, latiores, crassiores, supra et infra locate ita sunt disposite, ut lanimas medias, longiores tenuioresque et reliquum tubum in se recipere et condere possint. Dentibus terminatur duobus aut stylis depressis, medio exeuntibus.

Oviductus feminæ simplicior est et brevior. 'Tubus simplex exsertur inter laminas abdominis, apertus, xque bidentatus, sed dentibus brevioribus, lateralibus.

In specierum definitione nec color, nec declivitas elytrorum commemoratur. Ille semper niger hæc gradatim solummodo differt.

A. Blaptes thorace transverso, marginato.

\section{Blaps holconola.}

Bl. thorace transverso, marginato, levissime punctato; elytris sulcatis, sulcis subplanis, interstitiis punctatis, longe mucronatis.

Long. 13 lin. Lat. 6 lin.

Ratio raftiun:

capitis, thoracis, elytrorum, mucronis.

$\begin{array}{lcccc}\text { Long. } & 2 & 3 \% & 12 & 2 \% \\ \text { Lat. } & 3 & 5 \% & 8 & 1\end{array}$


Rlaps Gigas Fischer Entom. I. 184. t. XVI. f. 1.

Nomen gigantis improprium recusandum est. Numne hæc species ad depressam KuvgIr, secundum Com. Dejean (Cat. ed. 3. p.) referri debeat, affirmare nequeo, nam omnes hujus sectiones species sunt depressæ.

Labrum latum, antice rotundatum subemarginatum. Articuli antennarum globosi valde incrassati. Oculi semilunares.

Prosternum basi dilatatum, marginatum, inter pedes angustatum, apice intumidum, subglobosum, medio sulcatum. Netathorax punctato-sulcatus, apice elevatus.

Ilab. in Desertis Kirgisorum.

73. Blaps scutellata.

Bl. thorace transverso, marginato, margine late re. flexo, antice dilatato; profunde emarginato, postice scutello lato triangulari hirto; eljetris sulcatis, sulcis et interstitiis profunde punctatis, mucronatis, mucrone abbresiato, apice hiante.

Long. " $"$ "'" Lat. 9 lin.

Ratio rarticm:

$\begin{array}{lrrrr} & \text { capitis, } & \text { thoracis, } & \text { clytrorum, } & \text { mucronis. } \\ \text { Long. } & 2 \% / 2 & 4 & 11 & 1 \% \\ \text { Lat. } & 2 \% & 4 \% & 8 & 1\end{array}$

Caput magnum exsertum punclulatum opacum, 
labro angustato. Antennx graciles, articuli globosi parum incrassati. Oculi parvi, ovati.

Thorax transversus, antice dilatatus, profunde cmarginatus; marginatus, marginibus latis reflexis; supra punctatus, opaeus, canaliculatus, impressionibus quibusdam irregularibus. Seutellum triangulare, basi latum, hirtum, pulverulento-griseum.

Elytra ovata, medio dilatata, mucronata, mucrone brevi, ramis distantibus, inferius punctis impressis scabris, supra sulcata, sulcis et interstitiis punctatis, latere limbo tenui reflexo.

Corpus subsericei nitoris. Prosternum basi dilatatum, marginatum, parte interpedali angustatum, elevatum, profunde sulcatum. Metasternum latissimum, transversim sulcatum. Coxæ triangulares. Pedes punctati. Pulvilli unguicales longi, apice dilatati.

Hab. in Songoria. D. Karelin.

\section{BLaps stenothorax.}

Bl. thorace transverso, fere quadrato, opaco, antice posticeque impresso, marginato, marginibus reflexis, punctulato; elytris nitidis, medio dilatatis, seriatim punctatis, mucronatis.

$$
\text { Long. 1" } 4^{\prime \prime \prime} \text { Lat. 8"l }
$$

Ratio partium:

capitis, thoracis, elytrorum, mucronis.

$\begin{array}{lllll}\text { Long. } & 3 & 4 & 10 \% & 1 \% \\ \text { Lat. } & 2 \% & 3 & 8 & 2\end{array}$


Caput porrectum, labro transverso, antice rotundato. Oculi elongati valde compressi.

'Thoras transversus, elongato quadratus, opacus, antice impressus, medio paullo emarginatus, subcanaliculatus; tenuissime punctatus, postice impressione transversali, marginibus lateralibus medio late reflexis.

Elytra elongato-ovata, medio dilatata, nitida; costis binis subelevatis, dense seriatim punctatis, sutura impressa ad mucronem usque continuata; margines laterales in limbum acutum abeunt.

Corpus nigrum opacum. Coxæ pedum anteriorum fortes, cylindricæ, ita ut prosterno spatium angustum relinquant; hoc apice intumido elevato, sulcato. Pedes ut in reliquis. Pulvilli interunguicales abbreviato-dilatati.

Hab. in Tartaria magna. D. Pander.

\section{Blaps corrosa.}

Bl. thorace transperso, convexo, marginato; elytris elongato-ovatis, subparallelis, costatis, costis planis corrosis, latere punctatis, punctis impressis magnis profundis, mucronatis, mucrone debili, apice hiante.

Long. 1 poll. $4 \mathrm{\%} / \mathrm{z}$ lin. Lat. $7 \mathrm{lin}$.

Ratio partion:

capitis, thoracis, clylrorum, mucronis.

$\begin{array}{lcccc}\text { Long. } & 3 & 3 \% & 10 & 1 \% \\ \text { Lat. } & 3 & 4 & 7 \% & 1 \%\end{array}$


Caput exsertum, punctatum, ante oculos linea undulata impressum. Labrum transversum, antice dilatatum, emarginatum.

Thorax transversus antice dilatatus, gibbosus, marginibus lateralibus brevibus, subrellexis.

Elytra fere parallela, subnitida, costata, costis planis punctis impressis scabris et corrosis, interstitiis profunde et late punctatis, mucrone brevi, ramis supra sulco divisis, infra punctatis.

Corpus ut in reliquis. Pedes spinis abbreviatis scabri.

IIab. in Volhynia, Podolia australi, D. Besser; in Songoria, D. Karelin.

\section{Braps deplanata.}

Bl. thorace transierso; marginato, antice emarginato; eljtris medio.valde dilatatis, dorso deplanatis, concinne seriatim punctatis, brevi-mulcronatis.

Long. 13 lin. Lat. $6 \%$ lin.

Ratio Partium:"

capitis, thoracis, elytrorum, mucronis.

$\begin{array}{lllll}\text { Long. } & 2 \% & 3 \% & 9 & 1 \% \\ \text { Lat. } & 2 & 4 \% & 6 \% & 1 \%\end{array}$

Blaps deplanata, Méxétries. Cat. rais. zool. du Cauc. p. 199. n. 866 .

Falderman, Mém. de la Soc. de Moscou. V. 45. 316.t. VII. f. 1.

Nota. Non nisi unicum individuum possideo, sel 
si casus affirmativus plures negativos rejicit, dici potest articulos antennorum esse inæquales, 4, 5, 6 crassiores reliquis.

\section{Blaps quinque-costata.}

Bl. thorace subquadrato, marginato, margine angustato; elytris elongato-ovatis, crebre punctatis, quinquecostatis, brevi-mucronatis.

Long. 1 p. 3 lin. Lat. $6 \%$ lin.

$$
\text { Ratio partiun : }
$$

capitis, thoracis, elytrorum, mucronis.

$\begin{array}{lllll}\text { Long. } & 2 \% & 2 \% & 9 & 1 \% \\ \text { Lat. } & 2 \% & 4 \% & 7 & 1\end{array}$

Caput exsertum, opacum, punctulatum, labro transverso antice bi-emarginato. Sextus articulus antennarum reliquis crassior.

Thorax transversus, marginibus restrictis, antice parum emarginatus, subcoriaceus.

Elytra elongato-ovata, mucronata, crebre punctata; costata, costis quinque planis subelevatis.

Corpus reliquis simile. Mesothorax bidentatus. Pedes glabri, tibiis anticis longitudine sulcatis. Pulvilli inter-unguicales valde abbreviati, vix percipiendi.

Hab. in Songoria. D. Karelin.

78. Blaps muricata.

Bl. thorace transverso, marginato; elytris convexis, sulura impressa, confertissime rugosis. 
Long 13 lin. Lat. 7 lin.

\section{Ritio partium :}

capitis, thoracis, clytrorum, mucronis.

$\begin{array}{lllll}\text { Long. } & 2 & 3 & 9 & 1 / \mathrm{c} \\ \text { Lat. } & 2 & 4 \% & 7 & 1\end{array}$

Blaps muricata Fischer.

Faldenman, Mém. de la Soc. 1. c. p. 46. n. 37.

Hab. in Sibiria orientali;-in Caucaso.

B. TIIORACE SUBROTUNDATO PULVINATO.

1. ELYTRIS SUBDILATATIS.

79. Blaps Anthrax.

Bl. thorace rotundato, convexo, nitido, limbo tenui; elytris oblongo-ovatis, medio dilatatis; rugosis, opacis, sutura impressa, brevi-mucronatis.

Long. 1 poll. 4 lin. Lat. 7 lin.

Blaps Anthrax Steven, Fischer Mus. Univers. II. p. 69.

Similis Bl. Gagi Fabr. magnitudine, sed thorace extenso, elytris rugosis opacis, medio dilatatis, distinguenda.

Caput magnum exsertum, labro dilatato, transverso, vertice lævi, fronte punctulato-rugosa.

Thorax rotundatus, convexus, pulvinatns, tenue limbatus, glaber nitidus.

Elytra elongato-ovata, rugosa, opaca, sutura im- 
pressa, mucronata, mucrone debili, brevi, apice dehiscente.

Corpus punctulatum. Prosternum interpedali lato et intumido, apice obtuso. Pedes fortes. Pulvilli inter-anguicales conici, longissimi.

Hab. in Iberia. D. Steven.

(Mus. Stevenianum.).

\section{BLaps hians.}

Bl. thorace pulvinato, punctulato, antice paullo dilatato, non marginato; elytris medio subdilatatis, rugosis, sutura mucroneque subhiante.

Long. 16 lin. Lat. 6 lin.

Caput exsertum antice dilatatum. Facie linea semilunari impressa; labro transverso, medio costato, antice emarginato. Ultimus palporum maxillarium articulus valde dilatatus.

Thorax subquadratus, pulvinatus, subdepressus punctulatus, vix limbatus.

Elytra elongato-ovata, rugosa, sutura paullo elevata subhiante, mucronata, mucronc ramis fortibus, triangularibus, supra subhiantibus, latere subulatis, inferius deplanatis.

Nec corpus, nec pedes aliquid singulare offerunt. Pulvilli interunguicales abbreviati, triangulares, acuti.

Hab. in Podolia australi. D. Besser. 


\section{ELYTRIS ELONGATIS.}

81. Blaps ominosa.

Bl. clongata, nitida, fronte bifoveolata; thorace convexa punctulato; elytris clongato-ovatis, punctatis, costatis, costis obscuris, mucronatis, mucrone ramis longis cylindricis.

$$
\text { Long. } 15 \% \text { lin. Lat. } 6 \% \text { lin. }
$$

Blaps ominosa, Mévétriés Cat. Cauc. p. 198. u. 865.

Faldermane, Mém. de la Soc. V. 43. n. 314 . t. VII. f. 3. Blaps elongata, Karelix in lit.

Hab. in 'Turcomania, Armenia, Caucaso.

\section{Buaps Gages.}

Bl. elongata, nitida; thorace pulvinato; elytris lcevibus mucronatis, mucrone ramis cylindricis fere filiformibus, apice hiantibus.

\section{Long. 15 lin. Lat. 6 lin.}

Blaps Gages, Farr. Syst. Eleuth. I. 141. 1.

Blaps Gigas IIERbst.

Tenebrio Gigas Linnaei.

Hab. in Rossia meridionali.

Blaps armeniaca Faldermann Mém. da la Soc. V. 42. n.313. Tab. VII. f. 5. ita proxime huic speciei accedit, ut vix ac ne vix quidem ab ea distingui pos- 
sit. Puncta seriatim locata etiam in Gage oculo armato adparent.

\section{§3. Blaps producta.}

Bl. thorace rotundato vix limbato; elytris medio dilatatis, subsulcatis, mucronatis, mucrone abbreviato.

Long. 13 lin. Lat. 6 lin.

Blaps producta, Dejean Cat. ed. 3. p. 209.

Stubm, Cat. 1843. p. 149.

Hab. in Sibiria, Irkutsk ; - in Gall. meridionali, Hispania.

\section{THORACE ELONGATO-QUADRATO.}

1. ELYTRIS SUBPLANIS, APICE MUCRONATIS.

\section{Buaps Mortisaga.}

Bl. thorace quadrato, rotundatis marginato; elytris punctulatis mucronatis.

\section{Long. 12 lin. Lat. 4 lin.}

Blaps Mortisaga, Fabr. Syst. Elcuth. I. 141. 3.

Tenebrio mortisagus, Lins. Fauna suc. n. 822. Syst. Nat. II. 676. 15.

Schetfer, Icones, t. 36. 6. 6. 13.

Hab. in tota Europa. 


\section{.81}

85. Blaps confusa.

Bl. thorace quadrato, rotundato, rudi, subcanaliculato; elytris subsulcatis, obscurc punctatis mucronatis.

Long. 10 lin. Lat. 4 lin.

Confundi potest cum $B l$. mortisaga, sed paullo minor est; thorace subcanaliculato, elytris obliterate striatis aut sulcatis.

Caput exsertum opacum, epistomate quadrato, labro quadrato antice emarginato, ciliato.

Thorax quadratus, ¿subcanaliculatus, marginatus, punctis tenuissimis rudis.

Elytra subsulcata, punctulata, sutura impressa, latere versus apicem paullo dilatata, mucronata, mucrone brevi.

Corpus subnitidum. Prosternum basi dilatatum, limbatum, ferrugineo ciliatum, interpedale valde angustatum, sulcatum. Pedes fortes tibiis punctulatis, tarsis elongatis unguibus longis distantibus, pulvillo minimo.

Hab. in Podolia australi. D. Besser.

86. Blaps canaliculata.

Bl. thorace transverso, marginato, canaliculato; elytris subparallelis, pienctato-corrosis, mucronatis, mucrone longo canaliculato.

$$
\text { Long. } 13 \% \text { lin. Lat. } 6 \text { lin. }
$$

$N^{\circ}$ I. 1844. 
Blaps canaliculata Fiscir.
Blaps clongata Mannerin. $\quad y \begin{aligned} & \text { Dejean Cat. } \\ & \text { ed. 3. p. } 209 .\end{aligned}$

Caput productum, opacum, impressionibus binis longitudinalibus sub oculis. Epistoma linea recta distincto, quadratum. Labrum quadratum, antice inflexum, subsinuatum.

Thorax transversus latere paullo rotundatus, marginatus, dorso punctulato, subnitente, canaliculato.

Elytra subparallela, punctis corrosa, mucronata, mucrone longo, canaliculato. Sutura basi subelevata, postice canaliculata.

Corpus subnitidum. Prosternum basi latum, profunde sulcatum, interpedali longo, angusto, apice emarginato. Pedes debiles, femoribus punctatorudibus; tarsi Jongi, articulo unguicali longo, crasso, unguibus distantibus recurvis, pulvillo longo, cylindrico.

IIab. in Rossia meridionali.

87. Buaps reflexicollis.

3l. thorace transverso, lateribus subrotundatis, marginatis, margine subreflexo; elytris parallclis, punclis raris impressis, postice angustatis, mucronatis, mucrone longo, supra canaliculato.

Long. 13 lin. Lat. 5 lin.

Blaps reflexicollis Ziegl. Dejean Cal. ed. 3. p. 209.

Blaps pannonica Danl, Stura, Cat. p. 149. 
Caput excrtum opacum punctulatum. Epistoma medio linea impressa profunde notatum. Tabrum quadratum, antice subsinuatum.

'Thorax transversus punctulatus, marginatus, margine reflexo.

Elytra parallela, punctis raris impressis, postice angustata, mucronata, mucrone brevi supra late canaliculato.

Corpus opacum. Prosternum duabus impressionibus transversalibus donatum, apice abbreviato sinuato. Pedes femoribus anticis incrassatis, tarsis elongatis articulo unguicali supra canaliculato.

Mab. in Rossia meridionali.-Hungaria.

88. Buaps longicollis.

Bl. thorace transverso clongato antice angustato, glabro; clytris parallelis, crebre punctatis submucronatis, mucrone obtuso.

$$
\text { Long. } 11 \% \text { lin. Lat. } 4 \text { lin. }
$$

Blaps longicollis, Steven, Mus. Univ. p. 69.

Blaps clongalu, Fiscuer, Dejean, Cat. ed 3. p. 209.

Caput exsertum opacum nutans, epistomate linea incurva notato. Labrum quadratum, antice emarginatum.

Thorax transversus elongatus, antice angustatus, glaber, limbo tenui.

Elytra parallela, medio vix dilatata, arcte pun- 
ctata, mucronata, inucrone abbreviato, ramis crassis distantibus.

Corpus subnitidum. Prosternum sine impressione transversali, conus interpedalis valde incrassatus, apice dilatatus, sulcatus. Metasternum latum, transverse sulcatum. Pedes nihil observatu dignum offerunt, exceptis unguibus debilissimis, approximatis, pulvillo vix percipiendo.

Frequens habitat in Rossia meridionali, Podolia australi, Sibiria.

89. Blaps confluens.

Bl. thorace transverso, antice angustato, elytris punctatis, punctis impressis prope suturam seriatim positis, latere confluentibus.

Loug. 10 lin. Lat 5 lin.

Caput exsertum angustatum opacum, labro quadrato nitido, antice inclinato. Oculi albi.

'Thorax transversus, antice angustior, sublimbatus, punctulatus, subcanaliculatus.

Elytra parallela punctata, punctis prope suturam impressam seriation positis, latere confluentibus; marginata, mucronata, mucroni brevi ramis supra crassis conicis, medio canali sejunctis.

Corpus opacum. Prosternum dilatatum, antice angustatum sulco elongato.

IIab. in Volhynia; in Podolia anstrali.

尺. Blaps glabrata Besser, varictas procedentis, magnitudine et forma cum ea conveniens, punctis prope suturam minus distinctis. 
IIab. in Podolia australi; in Songoria; Fiscr. Cat. Col. Karel. 11. 145.

\section{Blaps coriacea.}

B1. thorace transverso, canaliculato, limbato; elytris parallelis brevi-mucronatis, punctato-granulato-scabris.

\section{Long. 12 lin. Lat. 4 lin.}

Blaps coriacea, Fiscuer Cat. Col. Karel. p. 14. n. 144.

Caput extensum punctulatum opacum, epistomate linea sinuata sejuncto; labro quadrato, antice emarginato. Antennæ ab oculis distantes sub epistomate inserte.

Thorax transversus, punctulatus, canaliculatus, limbatus.

Elytra parallela, sulcis quibusdam, punctis et granulis obliteratis coriacea; sutura maris impressa; mucronata, mucrone obtuse conico.

Corpus sericeum, rarissime punctulatum. Prosternum basi limbatum, valde impressum, inter pedes angustatum, apice dilatatum obtusum sulcatum. Pedes debiles, tarsis angustatis, unguibus debilibus adproximatis, pulvillis nullis aut brevissimis.

Hab. in Songoria. D. Karelix. 
91. Buaps seriatim-punctata.

Bl. thorace transverso limbato glabro; elytris parallelis, brevi-mucronatis, punctatis: punctis latis subrhomboidalibus seriatim impressis.

Long. 12 lin. Lat. 6 lin.

Caput exsertum opacum, vertice tinea transversa inter oculos impressa; epistomate linea semilunari sejuncto. Labrum subquadratum: antice dilatatum. Antennce vulgo tenuiores.

Thorax transversus, antice paullo rotundatus, sinualus, latere limbatus, postice recta abscissus lineaque recta transversa impressus, supra convexus glaber, medio canali brevi.

Elytra parallela, brevi-mucronata, punctata, punctis latis subangulatis seriatim impressis. Sutura tota longitudine impressa. Mucro parvan format adpendicem elytrorum, apice hiantem.

Corpus punctulatum sericem. Pedes femoribus punctulatis, reliquis partibus vulgaribus.

Hab. in Songoria. D. Karedin.

92. Braps microphthalma.

Bl. thorace transverso, antice dilatato, tenue lim-bato; elytris subparallelis punctis rariset sulculis transversis multivariis rudibus, mucronatis, mucrone abbreviato, obtuse conico.

Long. 10 lin. Lat. 4 lin. 


\section{7}

Blaps rarepunctata, Fiscuen, olim.

Caput dilatatum productum marginalum opacum, oculis compressis minimis, albis; epistomate quadrato; labro paullo angustiore quadrato; antice subemarginato. Antenne crassiores, articulis arcte contiguis.

'Thorax transversus antice rotundatus, obsoletissime punctulatus, postice recta abscissus, impressione transversa.

Elytra subparallela, punctis rarioribus sulculisque crebrioribus transversis rudibus. Sutura linea impressa notata; mucro brevis obtuse conicus.

Corpus sericeum. Prosternum quadratum, antice limbatum; interpedale breve sulcatum.

Pedes debiles, unguibus gracilibus, pulvillis nullis.

IIab. in Podolia australi. D. Besser.

\section{Blaps Carlo.}

Bl. thorace rotundato, marginato, canaliculato, depresso; eljtris subparallelis, glabris, brevimucronatis, sutura impressa.

Long. 11 lin. Lat. $4 \%$ lin.

Blaps Catrbo Steven, Fisch. Mus. Univ. II. p. 69.

Caput latum productum opacum, epistomate brevi, quadrato, antice sinuato. Antenne extrorsum pruinose. 
Thorax transversus, lateribus dilatis, margine reflexo, fere rotundo. Utrinque recta abscissus, postice cum linea transversa impressa. Canalis dorsalis abbreviatus.

Elytra bași parallela, dein sensim sensimque angustiora, tum in mucronem obtuse conicum abeuntiá; supra glabra, latere sublimbata.

Corpus opacum. Prosternum basi latum, inter pedes angustum, apice subdilatatum, emarginatum. Coxæ pedum anteriorum magnæ globosæ, lanie ferruginea tectæ.

Hab. in Rossia meridionali, ad Volgam.

\section{Blaps turcomana.}

Bl. thorace transverso, punctato, sublimbato; elytris elongato-ovatis, mucronatis, granulatis, granulis tenuissimis coriaceis.

Long. $10 \%$, lin. Lat. 4 lin.

Blaps turcomana, KarELIN in lit.

Caput magnum nutans, opacum, labro abbreviato subconico emarginato. Antenne fortes.

Thorax transversus, punctulatus, sublimbatus, antice sinuatus, postice recta abscissus.

Elytra elongato-ovata, tenue limbata, punctis et granulis tenuissimis coriacea, obliteratim trisulcata, mucronata, mucrone longo, supra sulcato, infra excavato.

Corpus subpunctatum nitidum. Prosternum basi profunde impressum, interpedale sulcatum. 
Pedes sibi invicem valde adproximati.

Ilab. in Turcomania. D. Karelin.

95. Blaps variolosa.

Bl. thorace transverso marginato; elytris elongato-ovatis, mucronatis, rugis et sulcis variolosis.

Long. 11 lin. Lat. 5 lin.

Caput nutans punctis rugosum, fronte excavata, epistomate brevi subtuberculato; labro subquadrato lævi, nitido, antice emarginato.

Thorax transversus, marginatus, margine reflexo, punctis scaber, opacus.

Elytra elongato-ovata, rugis et sulcis varie directis variolosa, mucronata, mucrone longo, supra angulato-sulcato.

Corpus punctulatum sericeum. Prosternum abbreviatum sed forma reliquis conveniens. Pedes graciles distantes.

Hab. in Sibiria,-Irkutsk.

96. BLaps acuminata.

Bl. thorace clongato, antice angustato, glabro; elytris parallelis, punctatis, mucrone deficscente terminatis.

$$
\text { Long. 9-10 lin. Lat. } 4 \text { lin. }
$$

Blaps acuminata Fiscuer, Entom. rossica. I. 187. t. XVI. f. 4. Hab. in Sibiria;-Nor-Saisan. 
97. Blaps seriata.

Bl. thorace transverso, lateribus subdilatatus; clytris clongato-ovatis, obliterate costatis, interstitiis, seriatim punctatis.

Long. 13 lin. Lat. 5 lin.

Blaps seriata Fiscuer, Entom. ross. 1. 185. t. XVI. f. 2.

Caput magnum. cxsertum nutans, opacum; epistomate angusto; labro quadrato, splendido, antice rotundato. Antenna articulis ultimis ferrugineopruinosis.

'Thorax transversus, Jatere subdilatatus; dorso convexo punctulato, impressione postica transversa.

Elytra elongata-ovata, basi constricta, medio dilatata, tenue limbata, obliterate costata, costis planis, interstitiis punctatis, punctis crassioribus, mucronata, mucrone valde obtuso, subtriangulari.

Hac species convexitate elytrorum formaque apicis transitum ad sequentem sectionem offert.

Corpus sericeum, lineis undulatis impressum. Pectus dilatatum, pedibus anticis ab intermediis distantibus. Prosternum abbreviatum inpressione transversa, interpedali angustato, elevato, medio sulcato; mesosternum dilatatum, impressione laterali transversa, dein in laminas duas sulco divisum; metasternum basi breve, apice elongatum bi-emarginatum. 
Pedes punctis impressis muniti.

Hab. in Bucharia. D. Pander.

98. Buaps scabra.

Bl. thorace transverso, ulinque attenteato, latere dilalato, limbato; elyoris subparallelis, submucronatis, sulcatis, sulcis, lineolis punctisque transuersis.

Long. 10 lin. Lat. 5 lin.

Blaps scabra, Fıscuer Cat. Col. Karel. p. 15. n. 149.

Caput porrectum latum, punctulatum, impressione transversali interoculari. Oculi glanci. Epistoma angustum quadratum. Labrum transversum apice emarginatum. Antenne coarctatex, articulis obconicis vulgo brevioribus, ultimis globosis.

Thorax transversus utrinque paullo attenuatus, antice subsinuatus, postice recta abscissus, lateribus dilatatis subrotundati, imbatis.

Elytra parallela, brevi-mucronata, sulcata, sulcis planis punctis et lineis transversis scabris.

Corpus subnitidum. Pedes nitidi, femoribus punctis impressis. Tibice antice profunde sulcate, bat si coarctatæ; pulvilli interunguicales brevissimi.

Hab. in Tartaria magna. D. Pander; in Songoria. D. Karelin. 
2. ELYTRIS CONVEXIS MUTICIS,'S. MUCRONE BREVISSIMO.

99. Blaps fatidica.

Bl. nitida, thorace subquadrato, latere dilatato, tenuc limbato; elytris subparallelis, convexis, crebre rudeque subseriatim punciatis.

Long. 11 lin. Lat. 4 lin.

Blaps fatidica, Creatzer. . .

Stuns Faun. germ. II. 205. n. 3. t. XLV. f. a. b.

Fischer, Entom. ross. I. 116-3. t. XVI. f. 3.

IIa. in Rossia meridionali; in Podolia australi.

\section{Buaps convexa.}

Bl. opaca, thorace transverso subcanaliculato; elytris elongatis parallelis convexis submucronatis, crebre inordinatim punctatis, sutura impressa.

Long. $10 \%$ lin. Lat. 5 lin.

Caput abbreviatum punctulatum opacum, epistomate quadrato linea subrecta sejuncto, labro quadrato, antice emarginato.

Thorax transversus subparallelus, tenuissime punctulatus, subcanaliculatus.

Elytra elongata, parallela, convexa, mucrone brevissimo; punctis crebris sublineatis inordinatim 1 mpressis. Sutura impressa et valde adparens.

Corpus opacum. Prosternum basi dilatatum, 
punctulatum, impressum, antice marginatum; interpedale valde elevatum, sulcatum; mesosternum valde dilatatum et inter pedes marginatum; metasternum basi obtriangulatum, abruptum, dein dilatatum, oblique transversim plicatum. Pedes glabri. Pulvillus unguicalis abloreviatus.

Hab. in Podolia australi. D. Besser.

Bl. cuspidatam Megerde ex Hungaria accepi convexce similem, mucrone tamen paullo longiore, corpore magis dilatato thoraceque convexiore.

\section{Blaps pterosticha.}

Bl. subnitida; thorace transverso, subparallelo, tenue limbato; elytris parallelis brevi-mucronatis, obliterate sulcatis, confertissime et inordinatim punctatis.

Long. 12-13, Lat. $5-6$ lin.

Caput magnum exsertum, vertice punctatum; epistomate lato quadrato: labro magno quadrato nitido, impressione profunda ab epistomate sejuncto, antice rotundato. Antennæe articulis abbreviatis.

'Thorax transversus convexus subparallelus subcanaliculatus, latere late marginatus.

Elytra parallela, obliterate sulcata, punctata, punctis impressis creberrimis; mucrone valde abbreviato, obtuso. 
Corpus sericeum, subtilissime punctatum. Pedes anteriores ab intermediis distantes. Prosternum basi triangulari rudi, interpedali valde angustato, apice dilatato, sulcato, emarginato; mesothorax valde dilatatus adpendice interpedali bi-emarginato; metathorax obcordatus, medio sulcatus. Tarsi antici coarctati unguibus gracillinis.

IIab. in Podolia, D. Besser; in Songoria, D. KARELIN.

\section{Blaps Fischeri.}

Bl. thorace transverso utrinque angustato; elytris elongato-oratis, distincte sulcatis, sulcis planis subnudibus.

Long. 12 lin. Lat. $51 / 2$ lin.

Blaps Fischeri, Karelin in lit.

Caput productum, punctulatum, linea interoculari impressa; epistomate quadrato, valde angustato; labro valde dilatato, medio excavato, nitido, antice subtriangulari, incurvo. Antennie valde breves, fere filiformes. Oculi nitidi.

Thorax transversus latere paullo dilatatus, rotundatus, angulis angustatis, dorso convexo punctato, antice posticeque recta abscissus.

lilytra elongato-ovata, brevi-mucronata, sulcata, sulcis angustis, planis, subnudibus, linea suturali distincta cum impressione triangulari scutellari.

Corpis opacum. Prostcrnum profunde sulcatum, 
apice profunde emarginatum; mesosternum valde dilatatum, medio sulco in ramos duos latos truplicatos divisum; metasternum Jatum, transverse su]catum, apice hi-emarginatum. Pedes elongati, tarsis anticis coarctatis, articulo ultimo forti, supra inciso, unguibus distantibus fortissimis, pulvillo elongato.

Hab. in Turcomania; Songoria. D. Karelin.

103. Buaps intrusa.

Bl. thorace transwerso, subparallela, canali dorsali profundo; elytris consexis glabris, punctis raris impressis, brevi-mucronatis, sutura forea triangulari lata notata.

\section{Long. $10 \mathrm{H} / \mathrm{s}$ lin. lat. $4 \mathrm{\%} / \mathrm{z} \operatorname{lin}$.}

Caput latum abbreviatum opacum, labro dilatato angulis rotundatis, antice sinuato.

'Thorax splendidus transversus subparallelus convexus, punctis minutissimis impressis, canali dorsali distincto, postice dilatato.

Elytra parallela convexa glabra, punctis raris impressis, sutura forea triangulari dilatata et profunda notata; mucro brevis, conicus, apice hians.

Corpus opacum Pedes femoribus punctulatis. Ungues debiles, pulvillo brevi.

Hab. in Tartaria magna, Songoria. 
104. Blaps nitida.

Bl. tota nitida; thorace transverso subconvexo; elytris subelongatis, subparallelis, seriatim punctatis, mucronatis, mucrone brevi acuminato.

Long. $10 \%$ lin. Lat. $4 \%$ lin.

Blaps nitida Steven, Fiscuer, Museum Universit. II. p. 69.

Caput latum nitidum, medio fovea longitudinali; epistomate postice concreto, antice rotundato; labro quadrato, antice emarginato.

Thorax transversus angustatus, subconvexus, splendens, antice simuatus, postice linea tenui recta impressa, latere limbatus.

Elytra subelongata, subparallela, seriatim punctata, sutura impressa, mucronata, mucrone brevi acuminato.

Corpus nitidum. Pedes debiles.

Hab.....

105. Blaps brevis.

Bl. corpore abbreviato; thorace transverso, antice angustato; elytris subparallelis convexis muticis, ad suturam sulcatis, ad margines punctatis.

Long. $9 \%$ lin. Lat. $4 \%$ lin.

flaps brevis. Sturm. Cat. Fiscrier Cat. Col. liarel. p. 16.

Caput latum, vertice elevatione triangulari; labro 


\section{7}

quadrato, antice subrotundato. Antenne graciles.

Thorax transversus, convexus, nitidus, antice subangustatus.

Elytris subparallelis, convexis, punctatis, punctis impressis creberrimis sulcisque quibusdam obliteratis prope suturam utrinque.

Corpus opacum. Pedes debiles sibi adproximati. Mab. in Podolia. D. Besser.

\section{Braps obtusa.}

Bl. thorace transverso antice angustato; elytris obosatis, glabris, postire dilatutis.

Long. $10 \%$ lin. Lat. $5 \%$, lin.

Blaps obtusa Farricit Syst. Eleuth. I. 141. n. 4. Stura, Faun. germ. 2. 206. XliV.

Hab. in Podolia.

\section{0\%. Blaps songorica.}

Bl. thorace transverso, antice subangustato; elytris parallelis convexis punctis quibusdam irregulariter impressis rudibus.

$$
\text { Long. } 10 \% \text { lin. Lat. } 5 \text { lin. }
$$

Accedit ad varias formas, ad brevem, obtusum, varians in ipsa specie, recedit tamen antennarum

$\Lambda^{\circ}$ I. 1944 . 


\section{8}

crassitudine, thoracis forma atque elytrorum structura.

Caput latum porulosum, epistomate et Jabro quadrato, rudibus; hoc antice emarginato. Antennæ articulis omnibus incrassatis coarctatis, anticis subcylindricis valde abbreviatis.

Thorax trausversus antice subangustatus, tenuiter limbatus, limbo subacuto, latereque rotundato.

Elytra subparallela punctis raris impressis, sutura impressa, mucrone obtuso.

Corpus nitidum. Prosternum latum limbatum, interpedali angusto, apice incrassato, emarginato. Mesothorax latus, glaber, impressione ransversa profunda, interpedali bidentato.

Pedes fortes distantes.

Hab. frequentissime in Songoria. D. Karelin.

108. Buaps dorsata.

Bl. thorace transwerso, obscure punctulato, tenue limbato; clytris parallelis punctulatis, lateribus intumidis, dorso plano.

Long. 10-11 lin. Lat. 5-6 lin.

Blaps deplanala Bessen in lit.

Caput latum, punctulatum, opacum, epistomate quadrato valde angustato, labro quadrato, antice dilatato, emarginato. Antennx maris incrassata, femina graciliores.

'Ihorax transversus, latere rotundatus, tenue lim- 
batus, antice angustatus, sinuatus, postice dilatatus subrectus, dorso punctulato, leviter canaliculato.

Elytra parallela, latere intumida, dorso plana, punctulata; emucronata.

Corpus sericeum. Prosternum basi dilatatum, transversim impressum, adpendice interpedali valde angustato, elevato sulcato. Mesothorax abbreviatus, dilatatus, pedilus itaque intermediis anticis valde adproximatis. Metathorax ad basin dilatatus, ad apicem cordiformis. Pedes debiles.

IIab. in Pollolia australi. D. Besser.

\section{Blaps pritinosa.}

Bl. atro-corulca opaca; thorace elongato; elytris oratis, punctatis, confertim striatis, apice retusis, subdehiscentibus.

$$
\text { Long. } 11-12 \text { lin. Lat. } 4 \% 6 \mathrm{lin} \text {. }
$$

Blaps pruinosa, Evesrmane, Faldermane, Bull. de la Soc. des Nat. 1833. Tome VI. p. 53. (Ed. parisin. p. 21\%.)

Hab. in Deserto Kirgisorum.

\section{Buaps anana.}

Bl. sericea; thorace transwerso, antice angustato, latere sublimbato; elytris parallelis, consexis, bresi-macronatis punctatis, punctis magnis seriatim impressis. 
Long. 10 lin. Lat. 5 lin.

Caput latum punctulatum, linea vesticis trans-, versim impressa, epistomate postice recto, antice rotundato; labro quadrato, antice paullo restricto, recto.

'Thorax transversus, punctulatus, antice paullo angustatus et sinuatus, latere tenue limbatus, postice impressione magna triangulari.

Elytra parallela, convexa, brevi-mucronata, punctata, punctis magnis subdistantibus seriatim impressis. Sutura impressa in mucronem brevem continuatur ibique dilatatur.

Corpus sericeum. Pedes debiles.

Ilab. in Songoria. D. Karelin.

111. Buaps parvicollis.

Bl. thorace transverso lasi, postice restricto; elytris subelongatis parallelis convexis, seriatims punctatis.

$$
\text { Long. } 7-8 \text { lin. Lat. } 3-3 \% \text { lin. }
$$

Blaps parvicollis, Escnscnoltz.

Zunкоғ, Bull. de la Soc. I. 160. Pl. IV. f. 8. (ed. gall. 3. 38.)

Hab. in Deserto Kirgisorum. 
112. Butps Krynicki.

Bl. convexiuscula, sublucida; thorace marginato, plano, subcordato, punctulato; elytris ovatis, acumine brevi deluiscente, substriatis punctisque obliquis aut eminentibus scábris.

( Krynicki.)

Long. 8 lin. Lat. $3 \%$ lin. of $8 \%$ 4. 우

Blaps Kirnichi, Kareus.

Krynicki, Bull. de la Soc. I. 1827 p. 195. 11. 25. 26.

Hab. in desertis ad Orenburg.

113. Blaps damascena.

$B l$. thorace transwerso; elytris muticis, obliterate sulcatis, interstitiis punctis transversis aut lineis impressis scabris.

Long. 10 lin. Lat. 5 lin.

Blaps punctata, Besser in lit.

Caput latum, fronte punctulatum; epistomate q̧uadrato angustato, glabro; labro transverso nitido, antice rotundato.

Thorax transversus", latere paullo dilatatus et limbatus, subpunctulatus, subcanaliculatus, foveis duabus parvis, prope canalem medio.

Elytra parallela mutica, sulcata interstitiis punctis transversis aut lineolis impressis valde adproximatis hinc illinc confluentibus, scabris. 
Corpus opacum. Prosterum dilatatum basi, interpedali angusto valde elevato, apice emarginato. Mesothorax latus, medio transversim impressus, interpedali bilabiato. Pedes fortes punctati. Ungues longi graciles, pulvillo abbreviato.

llab. in Podolia. D. Besser.

\section{ELYTRIS GRANULATIS S. RUGOSIS.}

\section{Blapś rugosa.}

Bl. thorace transwerso, latere subrotundato; antice angustato; elytris punctis latis impressis et fossulis rugosis.

Long. 9 lin. Lat. $4 \%$ lin.

Blaps rugosa, Gebuer in lit.

Dejenn, Cat. ed. 3. p. 209.

Caput latum punctulatum, fronte lincis duabus transversis impressum; epistomate lato, angusto, quadrato; labro quadrato rugoso, antice subemarginato.

Thorax transversus, antice angustatus, postice punctulatus, linea transversa impressus, dorso plano, subcanaliculato.

Elytra parallela brevi-mucronata, punctis et foveolis impressis rugosa.

Corpus opacum, punctulatum. Pedes et ungues debiles, pulvillo abbreviato.

IIab. in Mongolia. 


\section{3}

115. Biars granulata.

Bl. opaca; thorace transverso, antice subdilatato, punctulato, limbato; clytris postice subdilatatis, granulis minimis obsitis.

Long. 9 lin. Lat. $3 \%$ lin.

Caput valde productum, punctulatum, linea interoculari profunde impressa; epistomate abbreviato; labro transverso, producto, splendente, antice emarginato

Thorax transversus punctulatus, antice subdilatatus, latere tenue limbatus.

Elytra elongato-ovata, mucronata, granulis minimis obsita.

Corpus sericeum. Prosternum inter pedes dilatatum profundeque sulcatum. Pedes conformes aliis.

IIab. in Sibiria, ad Nor-Saison; D. Gebler.

116. Blaps miliaria.

Bl. tota granulosa; thorace transverso, lateribus rotundatis; cl.tris convexis, submucronatis, impressione scutellari triangulari, granulis parvis creberrimis contiguis coriaceis.

Long. 11 lin. Lat. 5 lin.

Caput exsertum, fronte luberosa, facie tenuissi- 
me granulosa; epistomate linea undulata sejuncto; labro brevi splendido, antice incurvo.

Thorax transversus, tenuissime' granulatus, latere tenue limbatus; limbo acuto, paullo deflexo.

Elytra elongato-ovata, convexa, subacuminata, granulata, granulis creberrimis parvis contiguis, basi fossa triangulari scutellum amulante.

Corpus opacum.

Hab. in Sibiria; Nertschinsk.

\section{Blaps variolosa.}

b\%. thorace transverso, antice angustato; elytris plongato-oratis, submucronatis, spriatim granulatis, granulis elevatis planis, mediis majoribus.

Long. 9 lin. Lat. 4 lin.

Caput latum exsertum fronte elevata nitida; pars facialis punctulata. Labrum abbreviatum, antice dilatatum latere, medio subemarginatum.

Thorax transversus, subparallelus, antice subangustatus, sinuatus, dorso canaliculato, subpunctulato.

Elytra elongato-ovata, submucronata, seriatim granulata, granulis clevatis planis, seriebus mediis najoribus.

Corpus subnitidum. Peles debiles.

Hab. in Sibiria, Irkulsh; D. Stscuuris. 
118. Buaps transversalis.

Bl. thorace transverso, subparallelo, late marginato, antice paullo restricto, glabro; elytris parallelis brevi-mucronatis, rugosis: rugis latis profundis transversis.

Long. 11 lin. Lat. $4 \%$ lin.

Blaps transversalis, Gebler, in lit.

Caput latum productum, vertice transversim excavato; epistomate quadrato angustato ; labro quadrato, antice subemarginato.

'Thorax transversus subparallelus, marginatus, margine reflexo, antice paullo restricto, subconvexus, glaber.

Elytra parallela, tenue limbata, rugosa, rugis latis profundis transversis, mucronata, mucrone brevi, supra sulcato.

Corpus opacum, tenuissime vage punctatum. Prosternum marginatum, interpedali angustiore, apice crassiore, emarginato.

Pedes intermedii anticis adproximati, postici ab intermediis distantes.

Hab. in deserto Kirgisorum. D. Scurenk.

119. Buaps Clotzeri.

Bl. thorace transverso, granulato; elytris angustatis, granulatis: granulis subelongatis seriatim positis. 
Long. 7 lin. Lat, 3 lin.

Blaps Clotzcri, Kareur in lit.

Minima inter omnes Blaptes.

Caput punctulatum, impressione interoculari transversa. Epistoma dilatatum. Labrum abbreviatum, antice ferrugineo-ciliatum.

Thorax transversus, subtilissime granulatus, antice subangustatus, latere sublimbatus.

Elytra subparallela basi, sensim sensimque versus apicem nngustata, emucronata, seriatim granulata, granulis elongatis.

Corpus sericeum. Prosternum abbreviatum sulcatum. Pedes valde adproximati. Femora antica intumida, subcompressa, tarsis lilatatis, unguibus distantibus, pulvillo brevi.

Mab. in Mongolia. D. Karelin.

D. TIIOR ACE OBCOR DATO, PULVINATO, SCUTELLATO.

SUBGEYUS : PELTARIUM.

( zidrogıov, scutellum.)

Os magnum quadratum, epistomate quadrato transversion exsculpto;

Labrum magnum subquadratun, antice restrictum, profunde emarginatum.

Palpi fortes articulo secundo longiori, ultimo ovato, apice rotundato.

Mandibule fortes, sulcate, subito acuminatæ; 


\section{7}

Mentum crassum, medio profunde excisum, pedunculo cordiformi, medio costato insistente.

Antenne crassiores vulgo, articulo terlio longissimo, sequentibus brevi-obconicis, septimo crassiore reliquis, ultimo globoso-acuminato; acumine restricto piloso

Forma Blaptis thorace rotundato plerumque marginato, certe limbato, elytris subparallelis convexis, postice conico-rotundatis, sine mucrone. Femora pedum non compressa, suleo inferiore nullo. Tarsi reliquis similes.

\section{Peltarium ovatum.}

P. thorace transverso, antice suldilatato, rotundato; elytris parallelis, convexis, punctato-sulcato scabris.

Long. 11 lin. Lat. $4 \%$ lin.

Caput exsertum, opacum, nutans; epistomate subsulcato, latere limbato, antice subangustato. Labrum quadratum.

Thorax transversus antice subdilatatus et subrotundatus, utrinque subsinuatus. Scutellum triangulare, punctato-rude.

Elytra parallela, crebre et irregulariter punctata et sulcata, sulcis obliteratis. Sutura distincta.

Corpus et pedes punctata. Prosternum sulcos utrinque offert, ad terminum usque obtusum et intumidum productos.

Hab. in Volhynia; Podolia australi. D. Besser. 


\title{
$10 \mathrm{~S}$
}

\section{Peltarium bicostatum.}

\author{
Tab. 1I. f. 6.
}

P. thorace transverso sublimbato, medio impresso; el)tris granulatis bicostatis.

Long. 8 lin. Lat. $3 \%$ lin.

Caput productum nutans, epistomate recta sejuncto; labro quadrato antice emarginato.

Thorax transversus, postice limbatus foveisque duabus impressus, dorso subpunctulatus, subcanaliculatus. Scutellum latum basi, triangulare.

Elytra submarginata subparallela, costis binis parum elevatis instructa.

Corpus nitidum. Pedes fortes. Prosternum latum transversim foveolatum, quasi geniculatum, antice angustatum, sulcatum. Pedes postici longiores, tibiis longissimis.

Hab. in Songoria. D. Karelin.

122. Peltarium marginatum.

1'. thorace transwerso marginato ; elytris subparallelis convexis rudibus, opacis, marginatis, margine acuto reflexo.

Long. 12 lin. Lat. 5 lin.

Blaps marginata olim.

Caput productum, opacum, antice impressione 
transversa profunda; labro quadrato anterius sinuato.

Thorax transversus, subconvexus, opacus, marginatus, impressionibus triangularibus angulorum posticorum. Margo posticus rectus limbatus. Scutellum triangulare hirtum, basi valde dilatatum.

Elytra subparallela, convexa, punctation scabra, marginata, margine reflexo, acuto.

Corpus pedesque nihil singulare offerunt.

Ilab. in Songoria. D. Karelin.

123. Peltarium punctatum.

$$
\text { Tab. II. f. } 7 .
$$

P. thorace transverso marginato, subtilissime panctulato; elytris subelongato-oratis arctissime punctatis, lineis binis obliteratis impressis.

\section{Long. $10 \%$ lin. Lat. $5 \mathrm{lin}$.}

Caput magnum productum suboratum, vertice impressum, latere marginatum. Epistoma quadratum, semilunatum. Labrum hirtum antice rotundatum, emarginatum. Antenne contractx ita ut breviores vulgo adpareant; basi tenues, extrorsum crassiores.

Thorax trausversus, latere paullo dilatatus, limbatus, subtilissime punctatus. Scutellum magnum triangulare hirtum.

Elytra subovata, versus apicem paullo dilatata, 
creberrime punctulata. Sutura linea impressa notata, versus apicem in sulcum profundum terminans.

Corpus et pedes ut in reliquis, articulis tarsorum magis coarctatis. Pulvilli interunguicales rotundati, abbreviati.

Hab. in Sibiria.

\section{Peltarium caludatum.}

P. thorace transverso, antice rotundato ampliato, punctato-rudi, marginato; elytris elongatoovatis, convexis, mucronatis, obsolete sulcatis, granulatis, granulis minimis subseriatim dispositis.

Long. $11 \%$, lin. Lat. $3 \%$, lin.

Blaps caudata, Gebler in lit.

Caput productum, latum, subrude, opacum, inter oculos transversim excavatum. Epistoma quadratum, latissimum, latere rotundatum, rude; labrum augustatum, nitidum, antice subsinuatum.

'Thorax transversus marginatus, antice paullo dilatatus, subconvexus, subpunctulatus. Scutellum triangulare, rude, hirtum.

Elytra elongato-ovata, medio dilatata, convexa, apice mucronata, mucrone maris subito angustato, feminæ abbreviato, obtuso. Supra granulata, granulis tenuissimi irubatesssim dispositis; prope suturam sulcis binis vel trinis obliteratis. 
Corpus nitidum. Prosterum latum, Iransversim intumidum, versus coxas limbatum, interpedali angustato, profunde sulcato.

Hab. in deserto Kirgisorum. D. Schrenk.

\section{Peltariun halophilum.}

P. thorace transwerso marginato, antice paullo restricto; elytris parallelis convexis subglabris, submucronatis.

Long. 10 lin. Lat. 4 lin.

Blaps halophila, Fıscuer, Entom. ross. I. p. 190. Pl. XVI. f. 7 .

Scutellum parvum triangulare. Elytra tenue limbata.

Ill. Dejean hanc speciem tanquam varietatem elongate m. s. longicollis Steven considerat, sed thorax brevior est et minus angustatus antice, latere marginatus. Scutellum deinde distinctum eam adhuc magis removet. Nomen dictavit individuum, ore, palpis, pectore, tarsis, crystallis salinis plenum

Hab. prope lacum Inderskoë.

\section{Dila, Fischer.}

a $\delta \varepsilon \nu \lambda \sigma$, timidus.

Mentum magnum obconicum antice dilalatum sinuatum. Pedunculus abbreviatus quadratus. 


\section{2}

Palpi maxillares incrassati, articulis obconicis, tertio longissimo, ultimo obconico, recta truncato.

Mandibula fortes acuminatæ, externe profunde sulcatæ.

Labrum quadratum, antice late sinuatum.

Antenna femina crassiores, maris debiliores, articulo primo crasso, secundo elongato, basi anuulato, quatuor sequentes fere cylindrici, reliquis quatuor globosis, ultimo globoso-acuminato, acumine elongato.

Forma elongata, thorax pulvinatus, non aut vix limbatus, cum scutello distmeto Dilas a Blaptibus facile distinguunt.

Caput exsertum nutans, epistomate postice rotundato, antice linea impressa a labro sejuncto.

'Thorax pulvinatus, fere orbicularis, latere vix limbatus utrinque recta abscissus, scutello distincto.

Elytra elongata sensim sensimque angustata, plerumque glabra et Jevia.

Prosternum plerumque magnum, inter pedes angustatum, apice sulcato-emarginatum.

Pedes fortes, tibiis anticis subincarvis, apice cavo obliquo ad articulum, tarsi primum recipiendum instructis. 'Tarsi lati subtus spinosi, unguibus longissimis incurvis. Pulvilli interunguicales brevissimi, vix percipiendi. 


\section{$11: 3$}

126. Difa lavicollis.

D. thorace elongato pulvinato leve; elytris conicis extensis, postice angustatis lavibus.

Long. 2 lin. Lat. 5 lin.

Blaps levicollis, Gerber, Bullet. de l'Acad. de St. Pétersbourg. 18.1. n. 5.

Caput productum, subcoriaceum, labro transversim excavato, anlice sinuato.

Thorax elongato-rotundatus, pulvinatus, lavis, vix limbatus, scutello brevissimo, triangulari, hirto.

Elytra elongata conica opaca lrevia, sub lente punctis quibusdam impressis medio, limbo tenuissimo, apice singulatim rotundato-obtusa.

Corpus nitens. Prosternum basi latum, medio transversim sulcato, inter pedes angustatum, apice obtuso emarginato.

Mesothorax profunde impressus, Jongus et latus. Netathorax longus transversin sulcatus.

Pedes fortes. Scapula elongato-globosæ, dimidio frilosæ; coxæ longæ triangulares. Femora intumida, inferius sulcata, versus apicem spina s. tuberculo munita. Tibice fere cylindrice, incurve, apice spinis binis obtusis inequalibus instructa. 'Tar' si articulis dilatatis, gradation angustioribus, ultimus fortis, penultimo crassior. Ungues fortes distantes recurvis, pulvillis intermediis brevissmis.

Ilab. in Songoria. D. Karelix.

N.. I. 1844 . 


\section{Dira Bürii.}

D. thorace subtranswerso, elongato, pulvinato, marginato; eljtris subpunctatis, subcostatis.

Long. 13 lin. Lat. $4 \%$ lin.

Blaps Bärii, Fısmer Cat. Col Karel. p. 16. et 28.

Maximam habet similitudinem cum pracedente, sed magnitudine, thoracis forma sculpturaque elytrorum diversa.

Caput productum, fronte impressa, labro magno, submarginato latere.

Thorax elongato-rotundatus, sublimbatus, postice sinuatus foveisqueduabus impressis. Scutellum. triangulare, basi dilatatum, sulcatum.

Elytra parallela versus apicem paullo dilatata, convexa opaca, obliterate costata et punctata.

Corpus nitidum. Pedes debiliores.

Coxæ anteriores minores. Prosternum simile ei pracedentis sed interpedale dilatatum. Mesothorax sulco longitudinali.

Mab. in Songoria D. Karelin.

\section{Dica llerbslii.}

1). thorace transverso, marginato, impressionibus duabus posticis; elytris subparallelis, glabris, postice angustatis, acuminatis. 


\section{5}

Blaps Merbstii, Fiscuen, Cát. Col. Karel. P 20. n. 350

Caput productum, vertice punctis duobus impressis, facie impressione transversali profunta. Labrum subtransversum, antice siunatum.

Thorax transversus, marginibus rellexis parallelis. Impressiones conicie in angulis posticis. Scutellum magnum, triangulare, setosum.

- Elytra clongata, subpunctata, limbis lateralibus tenue rellexis, postice angustatis in apicem roturdum abeuntibus. Sutura linea impressa indicatá.

Corpus et pedes nitida.

Mab. in Songoria D. Karelir.

129. Drsa attenzata.

3). capite angustato; thorace transwerso medio subdilatato, convexo, glabro, limbo tenuissimo; elytris conicis glabris.

Long. 10 lin. Lat. 3 lin.

Blaps attenuala, Frscher, Entom russ. L. p. 188. Pl. XVl. f. S. Stuna, Cal. p. 149.

3laps cylindrica Dej. Cat. ed. 3. p. 209.

Frequentissima in Rossia meridionali.

130. Dila cylindrica.

5) capite dilatato; thorace transverso, subroturndo, convexo; elytris elongalis medio subdilatutis, consexis, sulcis quibusdum obliteratis. 
Long. 11 lin. Lat. 4 lin

Blaps cylindrica, Henest, Col. Tab. CXXXVIII. f. 4.

IIab. in Sibiria ;-in Podolia.

\section{Dila foreala.}

D. Ihorace transverso, submarginato; canaliculato, canali medio foveato; elytris sublimbatis, rudibus opacis, sulura impressa.

\section{Long. 8 lin. Lat. $3 \%$ lin.}

Blaps foveata, Fiscuer, Cat. Col. Karel. p. 14. n. 117.

Caput exsertum, opacum, nutans, labro quadrato nitido.

Thorax transversus, fere parallelus, limbatus, antice paullo dilatatus, coriaceus, canaliculatus, canali medio dilatato, profundo.

Elytra rudia, coriacea, subsulcata, sutura impressa, limbis lateralibus tenuibus.

Corpus sericei nitoris. Pedes fortes, femoribus anticis intumidis, tibiis incurvis. Pedes postici longiores graciliora.

Hab. in Songoria. D. Karelix.

\section{Dila sulcuta.}

D. thorace transverso, angustato, subparallelo, punctato; elytris medio dilatatis, sulcatis, interstitiis crenulatis. 


\section{7}

Caput exsertum vertice punctulato, inter oculos lincis dualuus semilunaribus impressis. Epistoma subquadratum. Labrum dilatatum, nitidum, antice rotumlatum. Antennx graciles fere filiformes.

Thorax transversus, angustalus, punclulatus apice basique recta abscissus. cutellum parvum tiangulare.

Elytra basi angustata, thorace non lationa, sein sensim dilatata, tandemque versus apicem iterum angustata, sulcata, interstitiis crenulatis; sutura elevata.

Corpus sericeum. Pedes debiles, distantes. Ungues longissimi furcati pulvillis intermediis nullis.

Nota. Forma et structura elytrorum recedit a characteribus Dile; videtur intermedia inter Peltarium et Dilam.

133. Dila Karelini.

D. Lhorace transverso, sublimbato; elytris rage punctatis.

Long. 12 lin. Lat. $4 \mathrm{lin}$,

Blaps Karelini, Gebler, Bull, de la Soc. X1Y.1841. p. 593, n 6.

In vicinis lacus Nor-Saisan.

Nota. Blaps montana Victor, (Bull. de la Soc. des Nat. Xl1. I839. 1. 62. P1. 11. C. e. huic sectioni iuserenda videtur. 
131. Dina philacoides.

D. abbreviata, submitida; thorace transverso, lateribus subrotundatis, sublimbatis, subcanaliculato; clytris parallelis, obliterate sulcatis, postice rotundato-declivibus.

$$
\text { Long. } 5 \% \text { lin. Lat. } 2 \% \operatorname{lin} \text {. }
$$

Prosodes brevis, Gabler in lit.

Minima species inter Dilas et Blaptes in universum, habitu Phylaci ant Platysceli similes.

Caput productum, rugosum, nutans; epistomateo quadrato, sulco profundo a facie distincto. Labrum albbreviatum, nitidum, antice subsinuatum.

Thorax transversus, latere rotundatus et sublimbatus, opacus, sulcanaliculatus. Scutellum, triangulare, rugosum.

Elytra parallela, obliterate sulcala, latere limbata, postice declivia, apice rotundato.

Corpus nitidum. Pedes adproximati. Prosternums latum, transversim sulcatum. Coxa pedum anticorum magnæ, semicylindricæ. Femora versus apicem tibialcm incrassatæ et triangulariter profunde fovcate. Thibix incurve, apice spinis obtusis duabus. Tarsi fortes, dilatati, unguibus distantibus, pulvillo valde abbreviato. Femora intermedia et postico compressa, incurval, curvatura corpori adaptata.

Ilab. in Songoria. D. Kafirin; in deserto Kirgisor um, D. Schrexk. 


\section{NTCTIPATES DUaAN.}

\section{Nyctipates carinata.}

N. Chorace transverso, subparallelo, marginuto; elytris parallelis opacis sublimbatis, costis binis obliteratis.

$$
\text { Loug. } 9 \text { lin Lat. } 3 \% \text { lin. }
$$

Nyctipales carinala, Dejean, Cat. ed. 3. 1. 209.

blaps angustala Zuekoff, bull. de la Soc. VI. 1833. p. 327. 11. 35 .

Caput magnum nutans, vertice valde intumido levi: epistomate non distincto; labro lato quadrato nitido, antice sinuato.

Thorax transversus, antice subdilatatus, latere marginatus, margine lato reflexo, angulis posticis paullo productis, et punctis duobus impressis, antice posticeque subsinnatus. Scutellum triangulare, breve, nudun.

Elytra parallela limbata convexa, punctis tenuissimis scabra, costisque hinis elevatis indistinctis.

Corpus nitidum. Prosternum sulcatum, interpedali lato elevato bisulcato. Pedes anteriores dislantes ab intermediis, his postici adproximati. Peles fortes, tibiis anticis incurvis extus carinatis denticulatis, denticulis minimis, superioribus partum distinctis. 'Tarsi fortes; ungues sine pulvillo intermedio.

liab. in 'Turcomania. D. Kanems. 
136. Nyctipates asperata.

N. thorace transverso, medio dilatato, marginato; elytris subparallelis convexis, granulis elevatis acutis aspera.

$$
\text { long. } 10 \% \text { lin. Lat. } 4 \text { lin. }
$$

Nyctipates curiacea, Desean, Cat. ed. 3. p. 209.

Blaps asperata, Zubroff, I. c. p. 330 . n. 36.

Caput latum productum, vertice punctatum antice punctis duobus majoribus impressum. Epistoma distinctum latum, linea semilunari a facie disjunctum. Labrum quadratum nitidum, antice sinuatum.

Thorax transversus, medio dilatatus, glaber, marginatus, marginibus minus reflexis. Scutellum triangulare rude.

Elytra latere paullo rotundata, limbata, convexa, granulis minimis subseriatim dispositis aspera.

Reliqux partes cum is pracedentis speciei conveniunt, exceptis tibiis anticis, qux denticulis, gradatim majoribus numero quinque ornatæ sunt.

IIab. in eodem loco.

\section{Nyctipates costala.}

$N$. thorace transverso, latere paullo dilato et late marginato; elytris subparallelis, brevi-mucronatis, costatis, costis planis depressis, interstitiis punctatis. 
Long. 10 lin. Lat. 4 lin.

Caput productum latum nutans, opacum, epistomate quadrato; labro abbreviato, antice sinuato.

Thorax transversus, Jatere dilatatus, late marginatus, margine reflexo. Scutellum latum, sed breve, hirtum.

Elytra subparallela, latere sublimbata, poctice subito declivia et in mucronem triangularem abeuntia, qui tamen in feminis ita brevis et obtusus est, ut elytra conice teminentur. Supra subdepressa, costata, costis planis depressis adproximatis, interstitiis medio Jeviter, latere distincte punctatis.

Corpus opacum. Prosternum limbatum interpedali profunde sulcato, apice emarginato. Pedes similes sunt is pracedentim, tibix tamen antica incurve et carinata quidem sunt nec denticulate.

Ilab. in Turcomania.

TAGONA Fiscier.

Entom. rossica. J. 179-183. PJ. IVI. C. 89.

138. Tacora tinodactyla.

T. thorace transverso, convexo, glabro, latere tenue limbato; el ytris elongato-oratis, acuminatis, obliterate sulcatis, sutura impressa; tarsis longissimis, articulis compressis. 
Long. 5 lin. Lat. 3 lin.

Maximam habet similitudincen cum T. macrop/ethalma, corpore vero angustiore et imprimis tarsis longissimis differre videtur.

Caput magnum vertice foveato. Epistoma postice linea semilunari scjunctum nitidum. Labrum guadratum splendidum, antice involutum.

Thorax transversus, antice paullo augustatus, latere sublimbatus, supra convexus, glaber.

Elytra elongato-ovata, postice acuminata, convexa, obsolete sulcata sutura impressa.

Corpus opacum. Peles graciles, tibiis tenuibus, punctis impressis rudibus. 'Tarsi longissimi, articulis compressis.

Femina thorax magis dilatatus, convexior, canaliculatus.

Elytra ejus convexiora, sutura impressi.

Mab. in Turcomania. D. Kareun.

\section{PLATYSCELIS LATREILle.}

139. Platyscells Iabialis.

Pl. dilatatus, nitidus; labro extenso triangulari; thorace glabro; elytris striatis, striis impressis distantibus.

Long. 6 lin. Lat. $31 / 2$ lin.

Caput magnum glabrum nitidum; epistomate quadrato, angustato; labro magno, prominulo, tri- 
angulari. Mandibulac fortes Jatere et apice prominulx.

Thorax quadratus, antice angustatus, postice dilatatus, angulis latis reflexis, convexus, nitidus.

Elytra obconica, nitida, basi ralde dilatata, striata, striis impressis distantibus. Stria in fundo sub lente videntur esse punctulata.

Corpus nitidum. Pedes splendentes, tibiis tarsiscque subpilosis.

IIab. in Anatolia. D. Wredemans.

* te Eebrionites.

CAlcar, Dejean,

140. Cilcar crassipes.

C. fuscus, nitidus; cruribus anticis et intermediis intumidis, rubris.

Long. 3 lin. Lat. 1 lin.

Paullo minor et convexior. C. clongato, et paullo major procero.

Caput magnum productum splendidum, nigrofuscum.

Thorax obovatus, postice restrictus, convexus, fuscus, splendens.

Elytra elongata convexa glabra nitida.

Corpus nigrum nitidum. Fenora pedum anteriorum et intermediorum valde intumida, quasi ve- 
siculosa, rubra. Pedes postici longiores, debiliores, femoribus xque rubris, tibiis tarsisque fuscis.

Hab. in Rossia meridionali. D. Kindermann.

\section{Calcar sulcatul.}

C. elongatus, totus ferrugincus; clytris sulcatis.

Long. 3 lin. Lat. 1 lin.

Magnitudine precedentis.

Omnes partes ferruginee sunt sive testacere. Caput magis abbreviatum, thorace magis dilatatus, elytra arcte sulcata.

Hab. in Rossia meridionali. D. Kindemann.

\section{* HELOPII.}

HELOPS, Far.

142. Helops sulcatus.

11. niger, opacus ; thorace marginato; elytris costatis, interstiliis profunde punctatis.

\section{Jong. 5 lin. Lat. $21 / 2$ liu.}

Melops damascenus Fisciner, olim.

Si illustr. Comes Drjean (Cal. ed. 3. p. 230.) II. damascenum ad subrugosum Crevtzen traxit, in nomine aut in insecto misso ipso error regnare videtur, nam costa elytrorum hujus speciei nihil habent commune cum rugositate qualicunque. 
Caput magnom productum nutans opacum: ("p)istomate masno, antice angulato, marginato; datro brevi al, episiomate fere toto abscondito.

Thorax quadratus, opacus, rudis, Jatere paullo dilatatus sublimbatus, postice angulis latis productis, ntrimpue impressionem linearem obliquam relinguentibus.

Elytra costata, costis elevatis crassis, interstitiis punctatis, punctis magnis profundis.

Corpus subnitidum. Pedes antici distantes ab intermediis, his postici adproximati. Mesothorax latus, antice marginatus, interpedali in conum acutum terminatum. Coxa intermedie et postice magur, dilatilie.

Mab. in Anatolia. D. Wredenand.

\section{STERNODES, Fischer.}

Bublet. de la Soc. Impériale des Naumal. 1837. N. IV. 1. 10. t. 1 .

143. Sternodes Mannerheimii.

St: parallelus, niger, opacus; thorace quadrato, antice profunde sinuato; elytris oblongo-orantis, sulcatis, sulcis trinis obliteratis, griseopilosis.

Long. 4 lin. Lat. 3 lin.

Forma et habitu primo intuitu ad eam Opatri accedit, sed forma thoracis et structura elytrorum, 
imprimis prosterni hoc insectum cum Sternode conjungi debet.

Caput abbreviatum; vertice punctulato; epistomate profunde impresso, angustissimo; labro ungrno, producto, apice reflexo, medio emarrinato.

Thorax quadratus, antice profunde sinuatus, latere marginatus, marginibus utrinque prominentibus, supra convexus, glaber, opacus, postice linea undulata ab elytris sejunctus, his paullo latior.

Elytra oblongo-ovata, postice subarcuminata, convexa, sulcata, sulcis obliteratis hinis vel trinis griseo-pilosis. Margo eorum paullo reflexus, aeque griseo-pruinosus.

Corpus fuscum piceum. Prostemum processu digitali, elevato, gaudet, cum mesolhorace articulante.

Pedes maris nigri, feminx testacei. Femora antica incrassata; libix apice dilatate, trispinosæ ; tarsi abbreviati, articulis primis dilatatis, reliquis angustatis, unguibus longis, obtusis, distantibus, pulvillo nullo.

Hab. ..... Collectio Eschscholtziona, sine indicalione loci.

OPATRUM, FABR.

144. Opatrum granulosum.

0. fuscum ; thorace quadrato, marginato; clyris costatis, costis gramulatis. 


\section{7}

Long. 3 lin. Lat. $2 \%$ lin.

Opatrum gramulosum, Fiscuer, Cat. Col. Katel. p. 16 . n 148.

Caput trangulare, antice dilatatum, punctulaltum.

Thoras quadratus, marginatus, marginibus antice prominulis, caput fere tolum amplectentibus; convexus, punctulatus.

Elytra granulata, tricostata, costis distinctius gramulatis.

Corpus opacum.

llab. in Songoria. D Karriax.

\section{1 仿. Opatrum intermelium.}

O. thorace quadrato marginato, punctulato-scabro; cl)eris prope suturam granulatis, latere quadricostatis.

Long. 3 lin. Lat. 2 lis.

Caput exsertum, rugosmm, medio transversim sulcatum, antice dilatatum.

Thorax quadratus, antice profunde sinuatus, postice bisinualus, latere maginatus, convexus, rugosus.

Elytra costata el granulata; gramulis crebris prope suturam, costis adproximatis quaternis latere, interstitiis punclatis.

Corpus oparum.

lab. in Rossia meridionali. 
146. Opatrum pruinosum.

O. elongatum, parallclum, totum pruinosus ; eljtris tricostatis.

Long. $3 \%$ lin. Lat. $1 \%$ lin.

Similis $O$. riennensi, sed longior, thorace magis parallelo, elytris tricostatis, qux bicostata sunt in riennensi.

Caput angustatum et abbreviatum griseo-pruinosum, oculis antennisque nigris.

Thorax quadratus, parallelus, non marginatus, antice subsinuatus.

Elytra elongata parallela, costis elevatis teruis.

Corpus nigrum opacum.

Hab. in Turcomania. D. KareliN.

* TAXICORNES.

BOLITOPHAGUS, FaBr.

ELEDONA Litreille.

147. Bomitopuacus tricostatus.

B. niger, elongatus; elytris tricostatis.

$$
\text { Long. } 4 \% \text { lin. Lat. } 2 \text { lin. }
$$

Caput subtetrangulare, inter oculos dilatatum, pusctulatum.

Thorax quadratus, latere tenue limbatus, antice 
sinuatus, postice undulatus, angulis ubique prominulis, convexus, scaber.

Elytra elongata scabra, costis tribus elevalis lavibus.

Corpus nigrum opacum.

Hab. in 'Turcomania. D. Karelin.

148. Bolitaphages granulatus.

B. niger, thorace levi parum marginato; elytris seriatim granulatis, granulis lavibus depressis.

Long. 4 lin. Lat. 2 lin.

Bolitophagus granulatus, Fıscher Cat. Col. Karel. p. 16. II. 148 .

Caput subtriangulare, medio transverse sulcatum, labro magno emarginato.

Thorax opacus marginatus, antice posticeque profunde sinuatus.

Elytra subparallela, versus apicem subdilatata, marginata, granulata, granulis parum elevatis; aliis elevatioribus costas tres formantibus.

Corpus et pedes parum nitida.

IIab. in Songoria. Unicum specimen Societati misit Cl. Karelin.

$N^{\circ}$ I. 1844. 
* VESICANTIA.

MYLABRIS, Fabr.

Tab. III. f. 2.

149. Mrlabris elegantissima.

11. rillosa, nigra; elytris pallide flavis, fasciis

binis latis sinuatis, lunulaque apicis pigris.

Long. 8 lin. Lat. 3 lin.

Arylabris elegantissima, Zubroff, Bull. de la Soc. 1837. N. V. p. 79. PI IV. f. 4.

Hab. in Turcomania. D. Karelin.

\section{Mylabris Tauschleri.}

'Tab. III. f. 4.

MI. nigra; clytris pallide flaris, punctis magnis incequalibus humeri et apicis, fasciaque media sublunata nigris.

Long. 5 lin. Lat. $2 \%$ lin.

Mylabris Tauscheri, Escnscholtz, Desean, Cat. ed. 3. p. 242.

Caput magnum nitidum, antemnarum articulis ultimis griseo-villosis.

Thorax rugosus, niger, cum impressionibus vulgaribus.

Elytra pallide flava, punctis et fascia nigris. 
Puncta ant potius macule dux baseos sunt inaquales, altera externa marginalis major et elongata, altera interna sive prope suturam minor, subelongata. Macula apicis fere quadrangularis ad-. paret. Fascia media sublunata aul forman S transversim locali simulat.

Hab. in Turcomania. D. KArelin.

151. Myiabris undecim-punctata.

'Tal, HI. f. 3.

M. dense cillosa, nigra, elytris pallide flavis, punctis quinis unoque apicis suture communi nigris.

$$
\text { Loug. } 5 \% \text {, lin. Lat. } 2 \text { lin. }
$$

Mylabris undecimpunctata, Fischer Cat. Col. Karel. p. 17. n. 120 .

Caput magnum dense villosum, antennis nigris mudis.

Thorax niger, dense sriseo-villosus, canaliculatus, postice transversim impressus, supra medio punctis tribus impressis splendidis.

Elytra pallide flava, punctis quinis inequalibus moque apicis suture utrique elytro communi nigris.

Mab. in Songoria. D. Karelin. 
152. Mylabris octonotata.

11. villosa, nigra; elytris pallide flavis punctis octo incequalibus nigris.

\section{Long. 4 lin. Lat. 2 lin.}

Mylabris octopunctata, Fiscirer, Cat. Col. Karel.p. 17.n. 119.

Quandam habet similitudinem cum præcedente sed minor est, villositas ejus rarior puncturaque elytrorum diversa.

Caput nigrum nitidum fere nudum cum antennis raro pilosis.

Thorax niger, griseo-pilosus, profunde canaliculatus, punctis duobus latere impressis.

Elytra pallide flava, punctis inæqualibus nigris : 2, 2, 3, 1. Puncta prope suturam majora sunt et elongata, externa s. marginalia minora; punctum apicis fere triangulare.

Hab. in Songoria. D. Kapelin.

\section{Mylabris intermedia.}

\section{Tab. III. f. 5.}

M. atro-azurea; elytris ochraccis, fascii binis et lunula apicis atro-cœruleis.

Long. 5 lin. Lat. 2 lin.

Videtur esse intermedia inter variabilem BrLL- 


\section{3}

nenc, et variegatam Iltiger, sed multo minor est et fascia diversa forma.

Caput magnum nitidum, atro-cocruleum.

'Thorax cjusdem coloris; non pilosus, fere. glaber.

Elytra ochracea subpunctulata, fasciis et Junula atro-coeruleis. Fascix potius maculas magnas reprasentant medio petiolo parvo confluentes. Lunula apicalis magna, lata est et prope suturam paullo adscendit.

Hab. in Songoria. D. Karelin.

154. Mylabris marginata.

Tab. III. f. 6 .

M. atro-cerulea; clytris flarescentibus, linea marginali lamata punciisque quatuor atro-coruleis.

\section{Long. $4 \%$, lin Lat. 2 lin.}

Elongata et angustata.

Caput valde dilatatum, intumidum, atro-eoeruleum nitidum, antemnis nigris.

'Thorax ejusdem coloris pilis raris obsitus, impressionibus vulgaribus.

Elytra elongata ochracea, linea hamata aut polius vitta inferius sinuata punctisque quatuor atro coeruleis; puncta tria sunt suturalia, suture communia eanque tota longitudine limbo tenui 
nigro cingentia, qui in lunulam apicis vix percipiendam terminatur.

Non ignoro, Fabriciun speciem nomine Mylabridis marginalce designasse, (Syst. Eleuth. II. P 82. n. 6); verum enim vero hæc, teste Billberg (Monogr. Mylabris. p. 73 ), secundum typum in Museo .Paykull, Lyttce species est.

Hab. in Dauria ;-in Songoria.

\section{Mytabris quadrisignata.}

M. atra; elytris nigris, macula longitudinali humerali fasciaque sersus apicem flavis.

Long. $4 \%$ lin. Lat. $1 \%$ lin.

Nylubris quadrisignata, Genter in lit.

Similitudinem quandem offere videtur cum marginata, sed coloribus mutandis.

Caput nigrum nitidum, antemis extrorsum valde incrassatis.

Thorax niger, nitidus, raro-pilosus, utrimque restrictus.

Elytra elongata, atra, macula longitudinali s. vilta abbreviata humerali et fascia lata sinuata versus apicem ochraceis.

Hab. ad fluvium Kalfkir. D. Gébler. 


\section{5}

\section{Y'l'T'A Fabricir.}

156. Lytтa togata.

'Tab. III. f. I .

L. villosa, viridi-cenea; elytris punctulatis, vittu marginali lata coccinco-aurea.

Long. 8 lin. Lat. 3 lin.

L.jtla togata, Fiscuer, Cat. Col. Karel. p. 17.

Magnitudine Lytte vesicatorice et paullo major.

Caput magnum, viridi-seneum, punctulatum, oculis aureis, ore piloso; antemnis nigris nudis.

Thorax viridis, raro-pilosus, punctulatus; impressionibus vulgaribus. Scutellum magnum triangulare.

Elytra smaragdino-viridia, punctulata, s. tenuissime granulata, vilta marginali lata flavo-aurea.

Corpus aneo-nitens, pectore viridi, totis pilosis. Pedes coccinei coloris.

Mab. in Songoria. D. Karelin.

\section{ADDERF, LiCEAT SEQUENTIA:}

Conferenda: Analecta ad Faunam insectorum rossicam; Fischer in Bull. de la Soc. IV. I 832. p. 428-440. c. tabh. V. VI.

Recenter accepta :

\section{Carabus Stschutini.}

C. cupro-reneus ; thorace quadrato marginato pun.. ctato; el jtris elongato-ovatis, granulatis, gra- 
nulis planis distantibus triplici serie, interstitiis trilineatis.

Long. $9 \%$ lin. Lat. $4 \%$ lin.

Caput nigrum vertice lævi nitido, facie punctulata, oculis glaucis.

Thorax quadratus, cupro-æneus, punctulatus, marginatus, margine lato reflexo.

Elytra elongata-ovata, marginata ; granulata, granulis planis distantibus triplici serie, interstitiis lineatis, lineis trinis elevatis, adpressis, subcrenulatis. Margo punctatus, punctis latis impressis.

Corpus nigrum, nitidum. Prosternum latum, profunde sulcatum, post articulationem pedum subito geniculatum, et in conum deplanatum, in fovea mesothoracis articulantem, abiens. Coxæ posticæ latæ, depressæ.

In honorem Cl. Simonis Simonidis Srschurint, Sodalis nostri, Consiliarii Status, antea Directoris Gymnasii Irkutskensis, qui colligendis et conservandis insectis plantisque suæ regionis bene meruit de historia naturali Rossix.

Hab. in Dauria. D. Stscirukin.

158. Carabus dimidiatus. .

C. niger opacus; thorace subcordato, obscure anco; clytris clongato-ovatis granulatis, granulis elongatis interstitiis linea dimidiata parum elesata. 


\section{$1: 37$}

Long. 7 lin. Isat. 4 liu.

Caput nigrum, fronte levi nitida, oculis magnis prominulis.

Thorax subcordatus, subæneus, subpunctatus. submarginatus, marginibus parum reflexis.

Elytra elongato-ovata, nigra, opaca, granulata, gramulis elongatis, interstitiis punctis impressis rudibus. Dux linex elevatæ baseos inter suturam et primam seriem granulorum et inter hanc et tertiam abbreviatx, usque ad elytrorum dimidium tantum descendentes.

Corpus nigrum, opacum. Prosternum elevatum, leve, splendidum, apice subsulcatum.

Ilab. in Dauria. D. StschuкiN.

\section{Carabus interruptus.}

C. niger, opacus, subparallelus; thorace transverso; elytris costatis, costis parum elevatis, omnibus lineolis transversis interruptis, punctisque latis impressis triplici serie.

Long. $10 \%$ lin Lat. $3 \%$ lin.

Caput nigrum, opacum, oculis glancis, impressione interoculari profunda. Palpi Jongissimi.

Thorax trausversus, subtilissime pnnctatus, opacus, antice paullo dilatatus, marginatus, margine postice utrinque dilatato, exserto. 
Elytra subparallela, opaca, costata, costis angustis coarctatis, omnibus lineolis transversis impressis constanier interruptis. Puncta impressa triplici serie potius plana repraesentant, granula oblonga exserentia. Margo parum dilatatus, creberrime punctatus.

Corpus nigrum nitidum. Prosternum intumidum, elevatum, sulcatum, apice reque cum fovea mesothoracis articulationem inire videtur.

Hab. in Dauria. D. Stscuukin.

160. Necrophorus frontalis.

N. nigger, nitidus; clytris vage punctatis, femince immaculatis, maris vitta marginali maculaque rounda apicis subrubris.

Long. 1 poll. Lat. 6 lin. maris,

1 poll. 5 lin.-6- femina.

Magnam labet similitudinem cum N. germanico ; clypeus coloralus, vilta lateralis, antenna ejusdem coloris, sed frontalis germanico multo major est, vithque lateralis multo latior non nisi mari propriat est.

Capul maguum productum, fronte linea lyriformi circumscripta, glabra; splendida. Epistoma subtriangulare, marginatum, rubrum vel flavum. Labrum profunde cmarginatum, fuscum. Color epistomatis maris etiam in labrum transit sive trans- 
lucet. Vertex angustus, longुns, punctatus, nilidus. Antenne nigre, ultimo articulo clave fulvo.

Thorax rotundatus, nitidus, antice subsinuatus, latere et postice late marginatus et explanatus, disco convexo splendido, prope medium utrimque foveato. Scutellum magnum; triangulare, maris proportione majus, medio costatum.

Elytra niggra, nitila, vage punctata, maris vitta marginali et macula rotunda apicis admodum magnis flavis vel ferrugineis.

Corpus nigrum nitidum; pedes fortes, tibiis et tarsis anticis valde dilatatis. Prosternum breve, interpedali fere nullo, coxis magnis globosis sese adtingentibus. Mesothorax femina lense longeque pilosum, maris nudum.

Ilab. in Pucharia.

Nota. Cel. Grumenhal, Insecta suecica 1. p. 258. dicens, ohservatione ad germanicum: "variat rarius puncto apicis elytrorum rufon, frontalem tanquam varictatem rariorem germanici considerat.

161. Necrophonts particeps.

I. niger, nitidus; elytris punctato-subscabris, ritta marginali et fascia bi-lunulata apicis flaris,

Long. maris: $7 \mathrm{lin}$. Lat. $3 \% \mathrm{lin}$.

- femine: 9 - 4 - 
Magnitudine N. maritimi Eschscholrz et paullo minor. Characteres admodum inter utramque speciem conveniunt.

Caput nigrum, vertice et fronte canaliculatis. Epistoma feminæ flavo-maculatum, maris colore non tinctum. Oculi plani, nigri. Antennæ nigrie clava aurantiaca.

Thorax quidem rotundus et marginatus, sed impressionibus valde recedit a reliquis. Impressiones anticæ quatuor pariunt tubercula rotunda canalisque dorsalis postice tubercula duo majora producit.

Scutellum magnum triangulare, medio sulcatum

Elytra nigra nitida, punctis impressis scabra. Vitta flava marginalis angusta in fasciam apicis desinit bi-lunuJatam.

Corpus fere opacum. Mesosternum valde pilosum in utroque sexu.

Hab. in 'Turcomania.

162. Necrophorus sulcatus.

N. niger, immaculatus; elytris sulcatis, interstitiis punctalis.

Long. 7 lin. Lat 3 lin.

Minimus videtur esse hujus generis.

Caput valde productum, splendidum, oculis pro- 
minentibus magnis fuscis; fronte angustata, clongata, splendida. Epistoma quadratum. Labrum bifurcatum, ramis distantibus, medio setis ferrugineis repletum.

Thorax elongato-rotundatus, postice paullo restrictus, antice recta abscissus, ciliis ferrugincis donatus, impressionibus transversalibus; latere posticeque late et tenue marginatus.

Scutellum longum triangulare, basi fovea triangulari.

Elytra sulcata, interstitiis crebre punctatis.

Corpus opacum, mesosterno longe piloso.

Ilab. in Anatolia.

\section{PANDARUS Megerle.}

Dendarus, Dejean, Steven.

163. Pandarus femoralis.

P. niger, subnitidus; elytris obliterate punctatis, femoribus anticis compressis, versus apicem dilatatis, denticulatis.

Long. $6-7$ lin. Lat. $3 \%$ lin.

Caput nigrum, opacum, nutans, vertice et fronte punctulatis, impressione lineari inter oculos. Epistoma et labrum, quadrata nitida.

'Thorax subrotundus, pulvinatus, glaber, nitidus, tenue limbatus. Scutellum minimum. 
Elytra tenuissime et obsolete punctata, convexa, sericea, postice subacuminata.

Corpus nigrum, nitidum. Pectus simile Blaptibus. Femora antica compressa versus apicem dilatata, et inferius sulcata. Sulcus sæpius ita profundus est, ut versus apicem utrimque dentem s. adpendiculaun relinquat.

IIab. in Anatolia.

\section{INDD管}

\section{GENERUM COMMEMORATORUM.}

Acinopus. pag. 31 .

Adesmia. 58.

Atis. 59. 60.

Alpoeus. 26.

Anatolica. 65.

Aphodius. 45.

Blaps. 69.

Bolitophagus. $12 \mathrm{~S}$.

Calcar. 123.

Cantharis. 37.

Carabus. 11. 135.

Catalasis. 46.

Ceratistes. 35.

Cetonia. 51.
Chlienius. pag. 29.

Cicindela. 6.

Clerus. 39.

Cochlodera. 69.

Copris. 43.

Cryptarcha. 41.

Cyphonotus. 46.

Dasytes. 38.

Dendarus, 141.

Diesia 63.

bila. 111 .

Eledona. 128.

Guaptor. 69.

IIarpalus. 29 
IIclops. 124

l.ilsiostola. 58 .

l.ytta. 135.

Malachius. 36 .

Malthinus. $3 \%$.

Melolontha. 46.

Melyris. 38.

Mylabris. 130.

Nebria. 26.

Nitidula. 41.

Necrophorus. 40. 138.

Nyctipates. 119.

Ocnera. 55.

Onitis. 42.

Outhophagus. 43.

Opatrum. 126.

Pachyscelis. 54.

Pandarus. 141.

Peltarium. 106.

Pimelia. 53.
Pimelia. 58. 59. 60.

Platyope. 59.

Platyscelis. 122.

Podabrus. 33.

Pristonychus 30.

Pterocoma. 5 í.

Rhostax $6 \%$.

Scarabreus. 45.

Scarites. 31.

Sepidium. 60.

silplaa. 40.

sphodrus. 30.

Sternodes. 125.

Tagona. 121.

Tenebrio. 59.

Tentyria. 64.

Trachyderma. 5 s.

Trichodes. 39.

Trigonoscelis. 57.

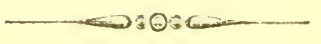

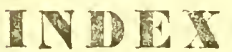

\section{T A B U L A F U M.}

Tab. I. f. 1. Cicindela Burmeisteri. p. 6.

2. - Sclirenkii. 10.

$3 . \quad$ Kirilevii. 7.

4. Cleonis imperialis, Karelin.

Conf. Bull. de la Soc. 1837. N. Y. p. 71. t. IV.f.5. 


\section{4}

Tab. II.f. 1. Dila levicollis, Gebler. p. 113.

2. - Bärii. 114 .

3. - Herbstii. 114.

4. - foveata. 116.

5. Peltarium halophilum. 111.

6. - bicostatum. 108.

7. - punctatum. 109.

Tab. III. f. 1. Lytta togata. 135.

2. Mylabris elegantissima, Zuвкоғғ. 135.

3. - 11-punctata. 131.

4. - Tauscheri, Escuscuoltz. 130.

5. - intermedia. 132.

6. - marginata. 133. 

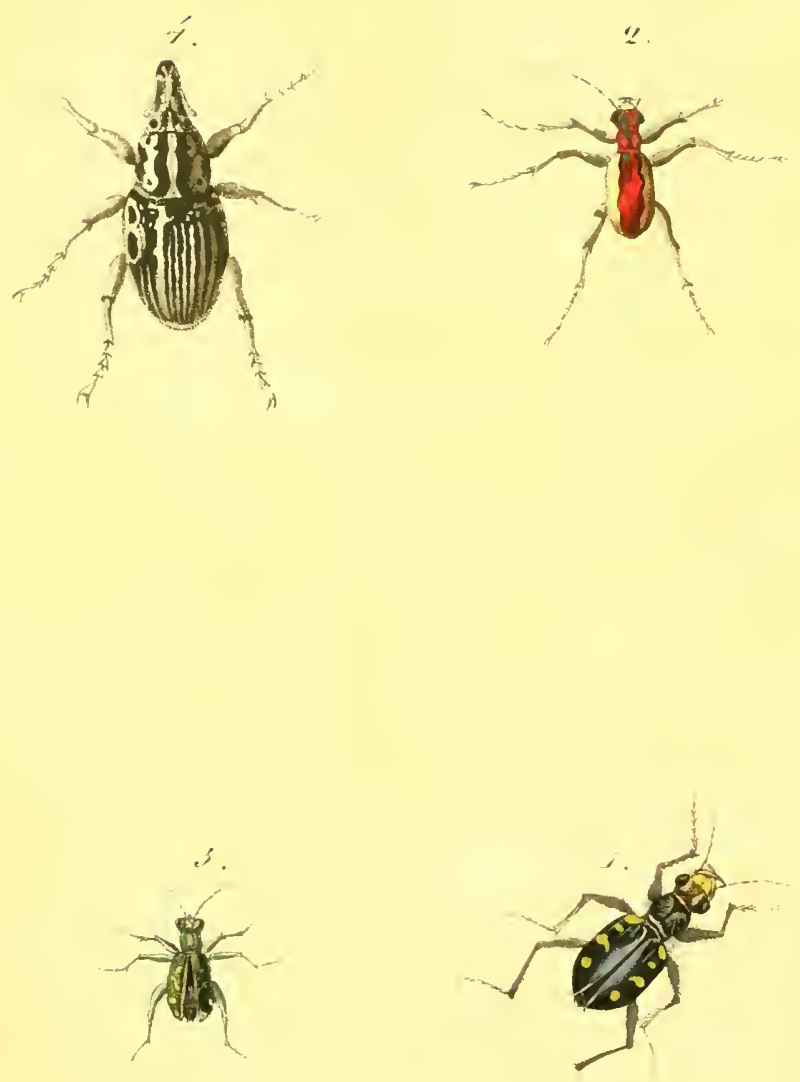

\section{(ivivitilit}

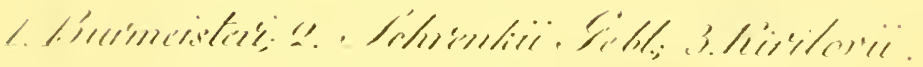

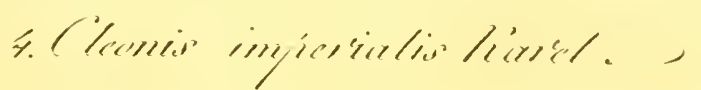




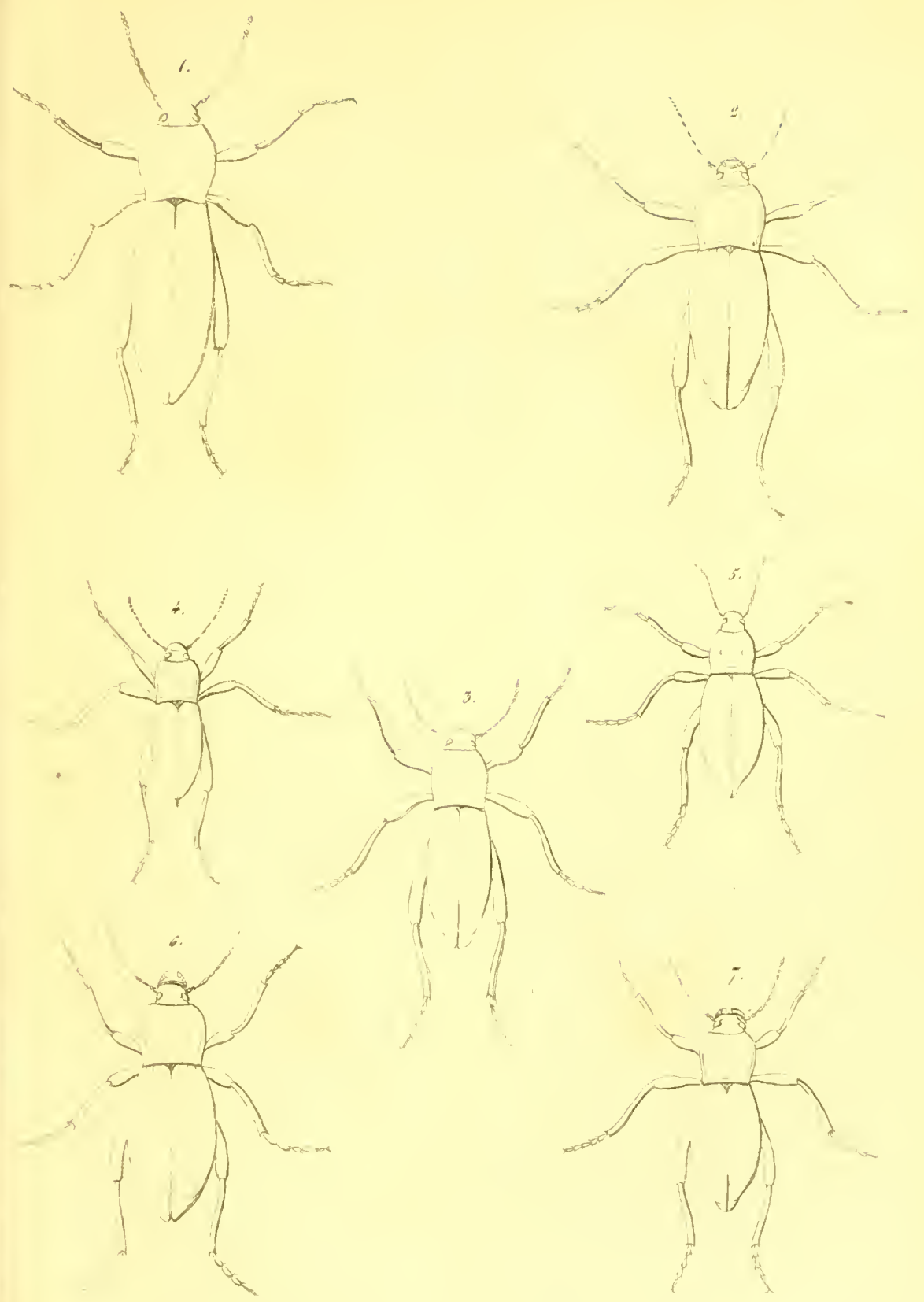

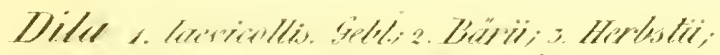

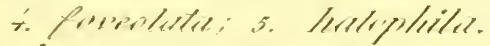

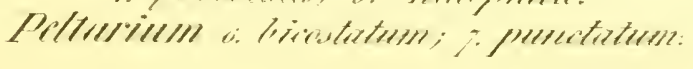




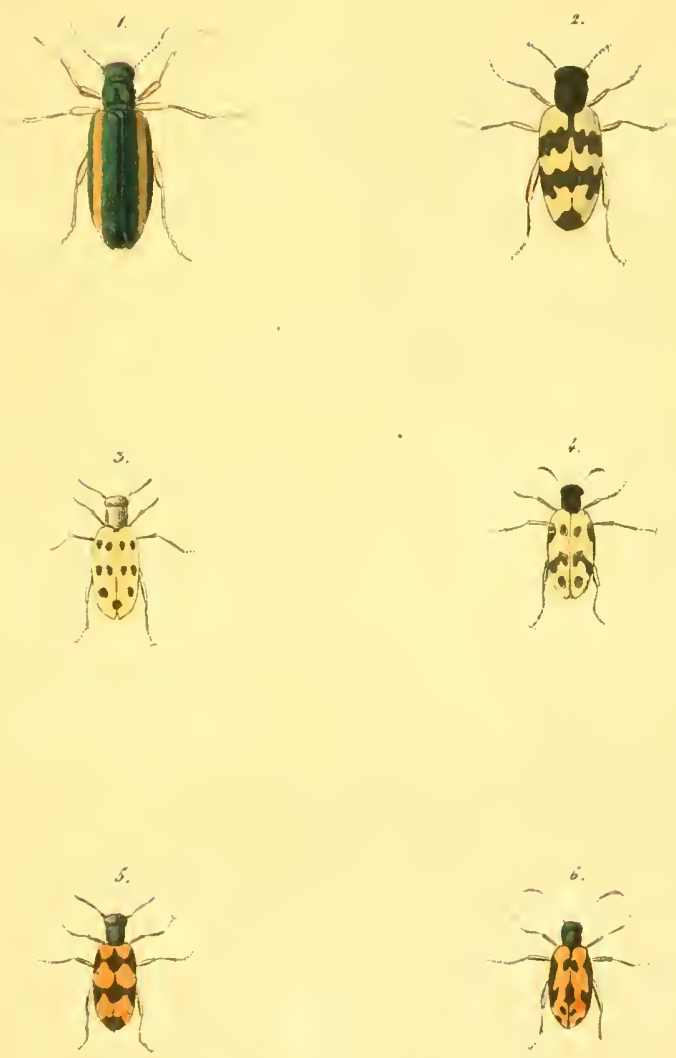

liplte r. Eonatis.

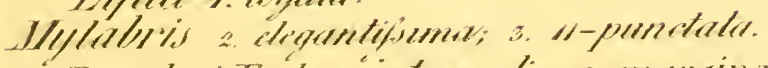

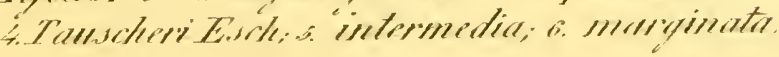





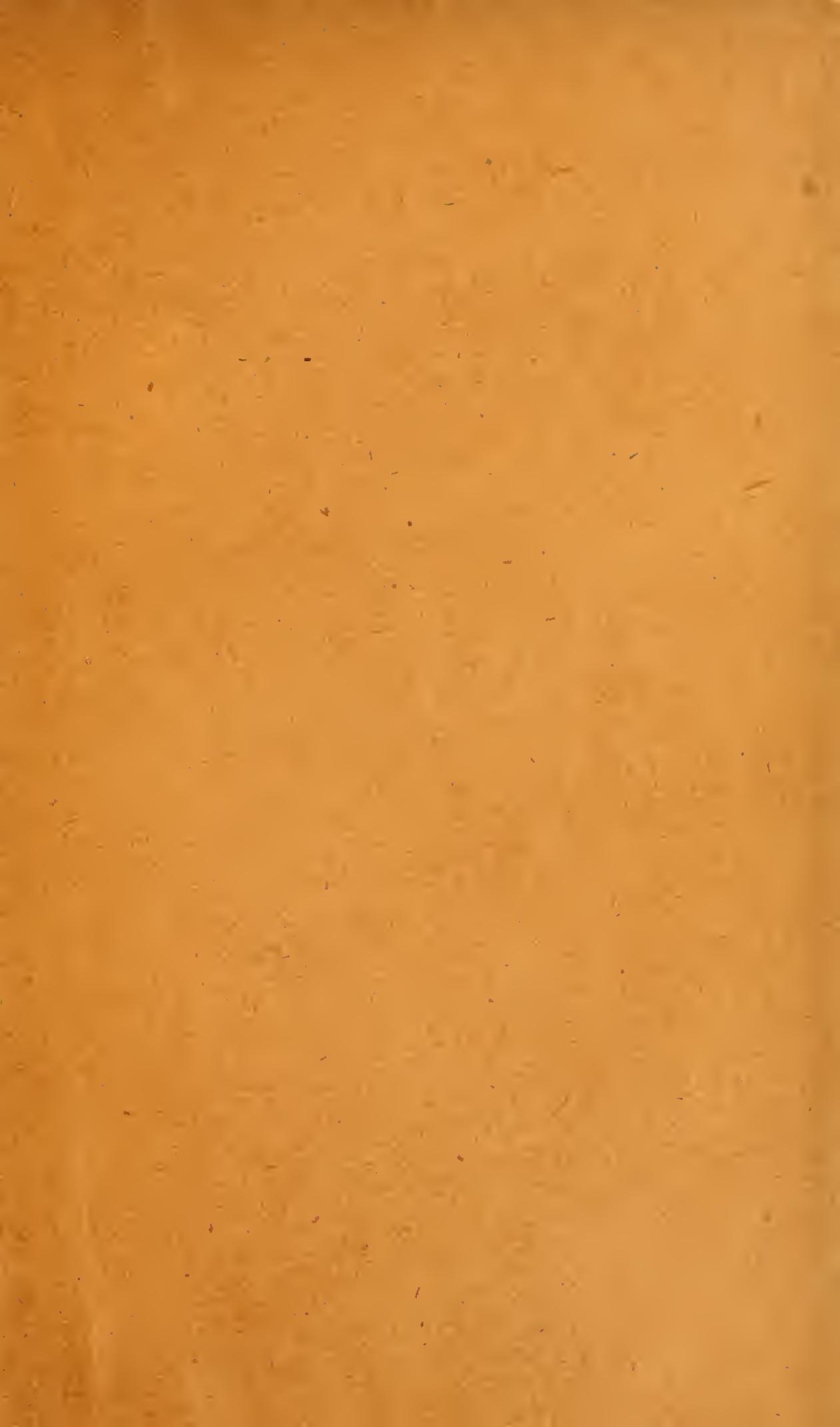







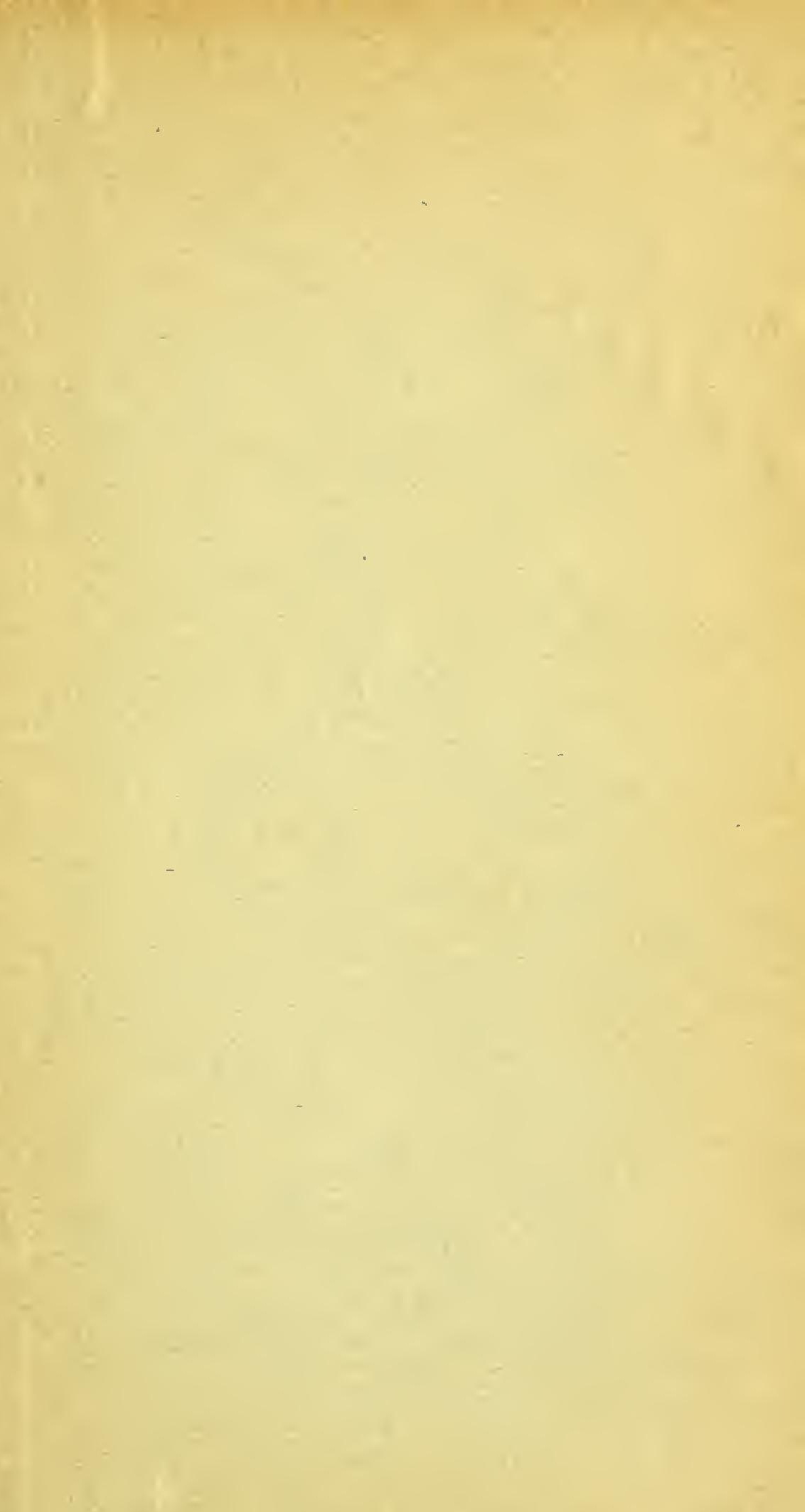


